\title{
EL CONCEPTO DE PATRIMONIO Y SU CONTENIDO EN EL DELITO DE ESTAFA*
}

\author{
THE CONCEPT OF ESTATE AND ITS CONTENTS IN \\ CRIMINAL SWINDLE
}

\begin{abstract}
ANDRÉS SCHLACK MUÑOZ*
RESUMEN: El presente trabajo trata del concepto de patrimonio y su contenido en relación con el delito de estafa. El autor sostiene para estos efectos un concepto jurídico-económico de patrimonio, el cual comprende todas las posiciones económicamente valiosas de que es titular un sujeto, en tanto no se encuentren expresamente reprobadas por el derecho. Se entenderán así como parte del concepto de patrimonio los derechos subjetivos patrimoniales, la posesión y las expectativas, entre otros elementos. Por el contrario, resultarán excluidas para estos efectos del patrimonio y de la protección penal del tipo de la estafa las obligaciones nulas por estar referidas a hechos inmorales o prohibidos por el derecho.

Palabras clave: Patrimonio, Perjuicio patrimonial, Estafa.

ABSTRACT: This work deals with the concept of patrimony and its content regarding swindle. The author states a juridical and economical concept of patrimony, which includes all the economically valuable positions of a person, as long as they are not expressly disapproved by Law. Therefore, the concept of patrimony includes patrimonial rights, possession and expectations, among other elements. On the contrary, obligations that are regarded as null and void because of being its content immoral or forbidden by Law are excluded from the concept of patrimony and no criminal liability for swindle shall arise thereof.
\end{abstract}

Key words: Patrimony, Patrimonial detriment, Swindle.

\section{INTRODUCCIÓN}

El Código Penal actualmente vigente en Chile (1874) destina el párrafo octavo del Título IX del Libro Segundo, artículos 467 a 473, a la regulación de la "estafa y otros engaños”. La redacción de estas normas sigue de cerca el Código Penal español de 1848

\footnotetext{
${ }^{*}$ Principales abreviaturas utilizadas: ANDCP $=$ Anuario de Derecho Penal y Ciencias Penales; $\mathrm{BGB}=$ Código Civil alemán; BGH = Bundesgerichtshof (Tribunal Supremo Federal alemán); BGHSt = Entscheidungen des BGH in Strafsachen (sentencias del BGH en materia penal, citadas por tomo y página); CC = Código Civil chileno; $\mathrm{CP}=$ Código Penal chileno; JMBLNRW = Justizministerialblatt für das Land Nordrhein-Westfalen; JuS = Juristische Schulung; JZ = Juristen Zeitung; LG = Landgericht; MDR = Monatschrift für Deutsches Recht; NJW = Neue Juristische Wochenschrift; NM = Número Marginal; $\mathrm{NStZ}=$ Neue Zeitschrift für Strafrecht; OLG = Oberlandesgericht; REJ = Revista de Estudios de la Justicia; RG = Reichsgericht (Tribunal Supremo del Imperio Alemán); RGSt = Entscheidungen des RG in Strafsachen (sentencias del RG en materia penal, citadas por tomo y página); StGB = Código Penal alemán; STS = Sentencia del Tribunal Supremo Español.

*Licenciado en Derecho, Pontificia Universidad Católica de Chile. (aeschlac@uc.cl aeschlack@gmail.com).
} 
y solo ha sufrido modificaciones de escasa entidad. Como lo han señalado diversos autores, la regulación adoptada padece de un profuso casuismo y de una falta de determinación clara de los elementos típicos que configuran el delito de estafa ${ }^{1}$. De ahí que se hace necesaria una labor dogmática acuciosa a efecto de establecer cuáles son dichos elementos típicos, delimitar sus contornos y precisar la función dogmática de cada uno de ellos. En cuanto a la identificación de los elementos, tal como en el derecho comparado, existe acuerdo entre los autores nacionales en señalar como exigencias típicas necesarias para la configuración de la estafa el engaño, el error, la disposición patrimonial y el perjuicio patrimonial, así como la relación causal de estos elementos entre $s^{2}$.

En nuestro medio, la doctrina ha tenido una aproximación al problema de la estafa que se ha centrado fundamentalmente en uno de sus elementos típicos, a saber, el engaño. La mayoría de los autores nacionales han pretendido fijar límites de idoneidad de este elemento por la vía de hacer suya la teoría de Carrara de la mise en scène $e^{3}$, en virtud de la cual no es suficiente para la configuración del delito de estafa una simple afirmación mendaz, sino que es preciso que se trate de una mentira acompañada de un despliegue de medios engañosos de índole externa ${ }^{4}$. Con toda razón, esta doctrina, abandonada por completo en la literatura comparada, ha sido criticada en tiempos recientes también entre nosotros dado su excesivo formalismo, proponiéndose en su reemplazo otras fórmulas más consistentes de idoneidad de la conducta engañosa, como, por ejemplo, criterios de imputación objetiva ${ }^{5}$.

Comparativamente, los restantes elementos de la estafa han recibido escasa atención en la doctrina y jurisprudencia de nuestro país. Así, urge un examen más detenido de dichos elementos, lo cual el presente estudio se propone realizar respecto de un aspecto del elemento típico del perjuicio patrimonial. Como resulta evidente, la determinación de un concepto de perjuicio debe estar precedido por la indagación acerca de qué concepto de patrimonio se ha de adoptar para los efectos del tipo de la estafa. En consecuencia, nuestra investigación pretende aportar a la discusión en torno al elemento típico del perjuicio indagando acerca del concepto de patrimonio y su contenido en relación con el delito de estafa.

Así, se sostendrá un concepto jurídico-económico de patrimonio, consistente en una unidad de valor compuesta por todas las posiciones económicamente valiosas de que es titular un sujeto, en tanto estas no se encuentren expresamente reprobadas por el ordenamiento jurídico. Como antecedentes necesarios del concepto a defender, se expondrán los conceptos jurídico y económico extremo de patrimonio.

\footnotetext{
${ }^{1}$ FernÁNdeZ (2005) pp. 181-193. En efecto, como lo señala este autor, del tenor literal del CP solo se desprenden los elementos típicos del engaño y el perjuicio patrimonial, no ocurriendo lo mismo con el error y la disposición patrimonial.

2 EtCheberry (1997) p. 392; Politoff et al. (2004) p. 418. Con todo, ha sido objeto de discusión si debe exigirse además como elemento subjetivo distinto del dolo el ánimo de lucro, aunque la opinión dominante se inclina por la negativa.

${ }^{3}$ CARRARA ([1859]1980) $\$ 2344$.

${ }^{4}$ ETCHEBERRY (1997) pp. 392 ss.

${ }^{5}$ FERNÁNDEZ (2005) p. 186 ss.
} 


\section{EL CONCEPTO JURÍDICO DE PATRIMONIO. EL PATRIMONIO COMO CONJUNTO DE DERECHOS SUBJETIVOS PATRIMONIALES}

\subsection{FORMUlaCión DEL CONCEPTO JURÍDiCO DE PATRIMONIO}

En orden cronológico, la primera teoría que intentó proporcionar un concepto de perjuicio patrimonial que permitiese dar cuenta de este como elemento típico del delito de estafa es la llamada teoría jurídica del patrimonio. Su desarrollo se debe fundamentalmente a Merkel $^{6}$ y a Binding7. El examen de esta teoría ofrece en la actualidad un interés más bien histórico, toda vez que, de ser la tesis dominante en Alemania a fines del siglo XIX, fue abandonada progresivamente por la jurisprudencia del RG, fundamentalmente a partir de RGSt 16,1 (sentencia de 20 de abril de 1887), y ya de manera definitiva con RGSt 44, 230 (sentencia de 14 de diciembre de 1910) . $^{8}$ Igual derrotero seguiría la doctrina alemana dentro de las primeras décadas del siglo XX, hasta el punto que quienes con posterioridad sostienen un criterio jurídico del patrimonio se encuentran en una posición absolutamente minoritaria, como es el caso de Naucke9.

La teoría jurídica sostiene una concepción del patrimonio que, en opinión de Binding, se traduce en la suma de todos los derechos y obligaciones patrimoniales de un sujeto de Derecho ${ }^{10}$. Tal como lo han señalado diversos autores, este concepto adoptado por Binding es una consecuencia natural de su teoría de las normas y de sus representaciones sobre el derecho penal como un derecho sancionador accesorio respecto de otros sectores del ordenamiento jurídico, correspondiéndole reafirmar a través de la sanción los preceptos previamente establecidos por otras ramas del Derecho ${ }^{11}$.

Es al tenor de lo anterior que señala Binding que la estafa, en cuanto delito patrimonial, se traduce en la lesión de derechos patrimoniales subjetivos cuya existencia, fundamento y contenido se encuentran dados de antemano por el derecho civil y, en ciertas ocasiones, incluso por el derecho público ${ }^{12}$. De ahí que la protección jurídico-penal del tipo de la estafa solo será posible en la medida que se afirme previamente la existencia de un derecho subjetivo en el sentido del derecho civil, lo cual Binding sintetiza en su célebre apotegma "Wo kein Recht, da kein Betrug" (Binding, [1902] 1969, p. 343), el cual podría traducirse como "Dónde no hay derecho alguno, no puede haber estafa"13.

Según lo destaca acertadamente Gallego, debe tenerse en cuenta que la noción de patrimonio desarrollada por Binding corresponde a una comprensión del mismo como

\footnotetext{
${ }^{6}$ Merkel (1867) p. 101.

7 BINDING ([1902]1969) p. 237 ss.

8 JAKOBS (1977) p. 228 ss.

${ }^{9}$ NAUCKE (1964) p. 214 ss.

${ }^{10}$ BINDING ([1902] 1969) p. 238.

${ }^{11}$ Antón OneCa (1957) p. 12; Gallego (2002) pp. 111-112; PAStor (2004) p. 33; Asúa (1993) p. 93. Para mayores detalles sobre este punto, BINDING ([1922] 1965); KAUFMANN ([1954]1977) p. 47 ss.

12 BINDING ([1902] 1969) pp. 239-240: "Aus der accessorischen Natur des Strafrechts ergiebt sich somit, was den Bestand solcher Rechte, ihre Begründung und Aufhebung, ihren Inhalt, ihre Zuständigkeit anlangt, seine vollständige Abhängigkeit von dem bürgerlichen Rechte".

${ }^{13}$ La traducción es nuestra.
} 
un inventario de todos los elementos que lo integran y no como una unidad de valor ${ }^{14}$. El mismo Binding dirá que no está permitido hacer abstracción de los derechos patrimoniales individualmente considerados y la transformación del patrimonio en una mera cantidad de contenido indiferenciado ${ }^{15}$.

\subsection{CONTENIDO DE UN CONCEPTO JURÍDICO DE PATRIMONIO}

La configuración del ámbito de protección de la estafa en torno a los derechos patrimoniales subjetivos considerados en su individualidad conlleva diversas consecuencias de interés teórico y práctico. En primer lugar, dicha protección se extiende a objetos dotados de un mero valor de afección, sin consideración a la falta de valor desde una perspectiva económica, toda vez que sobre tales objetos puede ejercerse el derecho de propiedad $^{16}$. Es así que Binding considera un gran progreso tanto científico como práctico la independencia de la teoría jurídica de criterios de valor pecuniario, en su opinión difíciles e inseguros ${ }^{17}$. Aclara el mismo Binding que debe considerarse cada derecho subjetivo como una parte integrante del patrimonio, aunque desde un punto de vista económico pueda aparecer como una carga ${ }^{18}$.

En segundo lugar, la teoría jurídica excluye como elementos integrantes del patrimonio aquellos negocios con objeto o causa ilícita, por tratarse de supuestos donde no puede apreciarse un derecho subjetivo amparado por las prescripciones del derecho civil. A este respecto, Binding hace mención del supuesto conocido como la "estafa de la prostituta" (Dirnenlohnbetrug), negando la existencia del delito de estafa respecto de aquel sujeto que contrata los servicios de una prostituta con el propósito de no pagar el precio pactado ${ }^{19}$ Otros supuestos análogos son el timo al alcahuete o quien encarga a otro la comisión de un delito a cambio de una remuneración, con la reserva mental de no pagarla ${ }^{20}$.

También resultan excluidos de la noción de patrimonio la tenencia de objetos que no puede ser reconducida a un derecho subjetivo stricto sensu. Tal es el caso del detentador antijurídico, del mero tenedor y del poseedor ${ }^{21}$. Binding reconocerá a la posesión como integrante del patrimonio solo desde una perspectiva económica, pero no jurídica 22,23 . Otro tanto ocurre con posiciones fácticas de indudable valor

\footnotetext{
${ }^{14}$ Gallego (2002) p. 111. En igual sentido Asúa (1993) p. 94; MaUraCH (1953) p. 247.

15 BINDING ([1902] 1969) p. 238: "Kriminalistisch ist es (...) unzullässig, von der einzelnen Vermögensrechte zu abstrahiren und das Vermögen zu verwandeln in eine reine Quantität von gleichartigem Gehalt".

16 BINDING ([1902] 1969) p. 239.

17 BINDING ([1902] 1969) p. 239 "Auch erblicke ich einen wissenschaftlichen wie praktischen Fortschritt in der Unabhängigkeit subjektiver Rechte von dem oft so schwer und unsicher zu handhabenden Wertbegriff"

18 Binding ([1902] 1969) p. 239. Proporciona aquí el clásico ejemplo académico de un caballo viejo y débil cuya manutención solo le reporta gastos a su propietario.

${ }^{19}$ BINDING ([1902] 1969) p. 343.

20 BINDING ([1902] 1969) p. 343

${ }^{21}$ BINDING ([1902] 1969) p. 343.

22 BINDING ([1902] 1969) p. 240.

23 Con esto hace eco BINDING de aquella corriente dentro de la privatística que concibe a la posesión como una cuestión de hecho y no de derecho, de la cual encontramos ya antecedentes en el Digesto, donde se sostiene que la posesión es una res facti (Dig. 41. 2. 1. 3; 41. 2. 29) doctrina que será retomada dentro de la pandectística alemana por SAVIGNY ([1803] 1870) p. 37 ss.
} 
económico en el tráfico en la forma de expectativas (Exspektanzen), como la clientela de un establecimiento de comercio, la clientela de un abogado o la expectativa cierta de un encargo lucrativo ${ }^{24}$. Es así que señala Binding que la estafa no protege la clientela, en tanto esta no esté contractualmente asegurada ${ }^{25}$. Por idénticas consideraciones tampoco se encuentra comprendida en la noción jurídica de patrimonio la llamada "fuerza de trabajo" (Arbeitskraft) ${ }^{26}$, cuyo concepto sintetiza Gallego como "la capacidad de prestar servicios -sean manuales o intelectuales- retribuibles" (Gallego, 2002, p. 117).

\subsection{CONFIGURACIÓN DEL PERJUICIO PATRIMONIAL}

Las consecuencias de la tesis jurídica en cuanto a la constatación del perjuicio patrimonial son también de importancia. Sostiene Binding que el perjuicio debe serlo en un sentido jurídico, referido a la lesión de derechos subjetivos, de modo que no puede el derecho penal admitir perjuicio patrimonial alguno donde el derecho civil lo niega ${ }^{27}$. Añade este autor que este concepto jurídico puede coincidir con el concepto económico de perjuicio, pero que ello no es en modo alguno necesario ${ }^{28}$.

El contenido de esta exigencia que hace Binding de un perjuicio en sentido jurídico se traduce en que este debe afirmarse por el hecho de no recibir el titular del patrimonio la prestación que es legítimamente exigible al tenor del negocio celebrado. Perjudicado es, por tanto, quien no obtiene lo que en derecho le corresponde ${ }^{29}$. Como puede advertirse de inmediato, esta formulación del perjuicio patrimonial se vincula íntimamente con la teoría privatística del incumplimiento de las obligaciones, como una manifestación más de la naturaleza accesoria que en concepto de Binding tiene el derecho penal frente a otros sectores del ordenamiento jurídico. Así, el perjuicio patrimonial se manifiesta en el incumplimiento de la obligación pactada, el cual se aprecia en los términos del derecho civil. Ello ocurrirá, presentado de un modo negativo, cuando no se satisfagan los requisitos que rigen el pago o cumplimiento, en especial el llamado principio de identidad ${ }^{30}$. Este último principio, recogido entre nosotros en el artículo 1569 CC, prescribe que "la prestación que se cumple debe empezar por tener contenido idéntico a lo estipulado, como manera de resguardarse el derecho del acreedor, a quien no se puede instar a recibir

\footnotetext{
${ }^{24}$ MaURACH (1953) p. 247. Dentro de estas "posiciones fácticas económicamente valiosas", no deja de ser justificado el asombro de 'GALlego (2002) pp. 117-118, ante la aceptación que sin más hace BINDING ([1902] 1969) p. 239, de los secretos empresariales como integrantes del patrimonio.

25 BINDING ([1902] 1969) p. 343: "Untaugliche Objekte des Betrugs sind also (...) die Inhaber von Kundschaften, sofern sie sich diese nicht vertragsmäßig gesichert haben”.

26 MAURACH (1953) p. 247; Cramer (1985) NM 96.

27 BINDING ([1902] 1969) p. 355: "Der Schaden muß sein ein Schaden im Rechtssinne. Handelt es sich um Schädigung von Privatrechten, so kann insbesondere das Strafrecht keine Vermögensverletzung annehmen, die das maßgebende bürgerliche Recht leugnet".

28 BINDING ([1902] 1969) p. 356.

${ }^{29}$ BINDING ([1902] 1969) p. 357: "der nicht erhält was er von Rechts wegen beanspruchen kann”.

${ }^{30}$ Sobre los requisitos del pago o cumplimiento en materia civil, ABELIUK (2001) pp. 562 ss.
} 
una prestación diversa, ni aun a pretexto de ser de igual o mayor valor económico" (Fueyo y Figueroa, 2004, p. 128) ${ }^{31}$.

Según se desprende de lo anterior, el perjuicio corresponde para la teoría jurídica a un concepto formal consistente en la pérdida de un derecho patrimonial subjetivo o su modificación de manera contraria a las previsiones permitidas por el ordenamiento jurídico ${ }^{32}$. Desde esta perspectiva, donde el objeto de la lesión es el derecho subjetivo en cuanto tal, será indiferente si la pérdida de tal derecho en sentido jurídico tiene o no una significación económica, con lo cual habrá perjuicio patrimonial aun cuando el objeto sobre el cual este recae no tenga un valor de cambio o que de la pérdida no se siga un menoscabo económico ${ }^{33}$.

Presentada así la situación, se hace imposible configurar una lesión al patrimonio considerado este como una unidad de valor ${ }^{34}$, sino que solo será concebible un ataque a los derechos subjetivos que lo componen. Esto no viene a ser sino una manifestación de la concepción que tiene Binding del patrimonio como inventario de sus diversos elementos a la que hicimos mención precedentemente.

Lo anterior tendrá por consecuencia la exclusión de la posibilidad de aplicar el llamado "principio de compensación" a efecto de negar el perjuicio toda vez que, por ingresar una contraprestación al menos equivalente a la disposición patrimonial, la valoración contable del patrimonio en su conjunto no haya sufrido un menoscabo. En efecto, dirá Binding expresamente que no cabe preguntarse por la ulterior compensación en sentido económico de la ganancia antijurídica del sujeto activo ${ }^{35}$. Es así que Maurach pone de relieve que, para quien suscriba la tesis jurídica, una compensación entre la ganancia y el detrimento sufrido (Gesamtsaldierung) debe descartarse inevitablemente, toda vez que la pérdida de un derecho individualizado no puede ser compensada de ninguna otra manera ${ }^{36}$.

Precisamente, la negativa de la teoría jurídica a entrar en consideraciones acerca del patrimonio como unidad de valor y, por el contrario, el énfasis puesto por sus partidarios en los elementos que lo componen como objetos de la lesión, hace que la pérdida jurídica de un derecho subjetivo sea, ya en sí misma, un perjuicio patrimonial típico. En suma, dicho perjuicio se afirmará sin que sea relevante si se recibió o no una

\footnotetext{
${ }^{31}$ La formulación que de este principio hace el Art. 1569 CC es la siguiente: "El pago se hará bajo todos los respectos en conformidad al tenor de la obligación". El origen del principio de identidad del pago lo encontramos a su vez en el Derecho Romano, como puede leerse en el Digesto: "Aliud pro alio invito creditori solvi non potest" (Paulo, Dig. 12, 1, 21,1).

32 Asúa (1993) p. 94; en idénticos términos GALlego (2002) p. 324.

33 BINDING ([1902] 1969) p. 240: "Im Rechstsinne ist Jeder an seinem Vermögen geschädigt, der ohne die Billigung des Gesetzes um sein Vermögensrecht oder um die Sache, an der es besteht, oder um die Möglichkeit seiner vollen Ausübung gebracht wird, sowie Derjenige, dem nicht geleistet wird, was er rechtlich zu fordern hat, und dem grundlos eine Leistungsflicht aufgelegt wird, ganz einerlei, ob wirtschaftlich jene Einbuße, wie in den weitaus meisten Fällen, sich aus als Verlust oder aber ausnahmsweise als Gewinn darstellt".

34 BINDING ([1902] 1969) p. 238. "Das Vermögen als eine einheitliche Wertmasse ist nie Angriffsobjekt des Verbrechens".

35 BINDING ([1902] 1969) p. 240.

${ }^{36}$ Maurach (1953) p. 247.
} 
contraprestación equivalente en cuanto a su valor económico, siendo suficiente la pérdida de un derecho o su gravamen, sin que se reciba a su vez lo que, al tenor de la obligación, le corresponde en derecho a la víctima.

Otra consecuencia de la noción jurídica de patrimonio será la negativa de sus partidarios a aceptar la existencia de un perjuicio patrimonial en los supuestos de puesta en peligro del patrimonio, sea que se trate de un peligro abstracto o bien concreto. Ello, en opinión de Binding, se explica por cuanto la puesta en peligro del patrimonio deja intacta la situación jurídica, por lo cual no implica un perjuicio ${ }^{37}$.

\subsection{CRÍTICAS}

La tesis de Binding sobre el patrimonio, en su formulación antes expuesta, ha sido objeto de numerosas críticas, las cuales explican su completo abandono por parte tanto de la jurisprudencia como de la doctrina en Alemania. Numerosos autores le han reprochado a la teoría jurídica que, según la perspectiva que se adopte, determina un ámbito de protección del tipo de la estafa que demuestra ser a la vez muy amplio y muy estrecho ${ }^{38}$.

Según lo expresa Maurach, el concepto jurídico de patrimonio es demasiado restringido al momento de satisfacer las exigencias del tráfico (Auforderungen des Verkehrs ${ }^{39}$. En efecto, la teoría jurídica se erige como un concepto "antieconómico" de patrimonio, toda vez que desconoce por completo la dimensión económica que a este le cabe $^{40}$. Así, al poner el énfasis exclusivamente en la noción de derecho subjetivo quedan desprotegidos, según lo adelantamos, una vasta gama de posiciones fácticas económicamente valiosas de una evidente relevancia para el tráfico, como la posesión, las expectativas, la clientela, el know-how, los secretos empresariales, etc. Como lo ha puesto de relieve Gallego, no puede desconocerse que el mismo ordenamiento jurídico le otorga protección a estas posiciones fácticas, aunque no en la forma de derechos subjetivos según la concepción clásica de estos ${ }^{41}$. Ello se hace particularmente notorio en el campo de la responsabilidad civil, admitiendo la doctrina privatística moderna que el concepto de perjuicio no solo comprende la lesión de un derecho subjetivo, sino también la afectación de intereses legítimos ${ }^{42}$. En razón de esto último, aun cuando se conceda por un momento la dependencia del derecho penal respecto de conceptos extrapenales ${ }^{43}$, no es tan evidente que el perjuicio "en sentido jurídico" que reclama Binding solo pueda ser tal en tanto se circunscriba a la noción del derecho subjetivo.

\footnotetext{
37 BiNDING ([1902] 1969) p. 360: "Eine vermögensgefährdung läßt den Rechtsbestand intakt und stellt deshalb keine Schädigung dar".

38 Maurach (1953) pp. 247-248; Gallego (2002) pp. 118 ss. ; Hernández (2003) pp. 172 ss.

39 MAURACH (1953) p. 247.

40 PASTOR (2004) p. 33.

41 Gallego (2002) p. 119.

42 Corral (2004) p. 139; Alessandri (1943) pp. 210 ss.

43 Frente a la concepción del derecho penal como un derecho sancionador en todo dependiente de otros sectores del ordenamiento jurídico, hoy suele admitirse que el derecho penal debe orientar el sentido de los conceptos jurídicos que emplea según sus propios fines de protección. En tal sentido, JESCHECK (1993) p. 46.
} 
A su vez, de adoptarse la teoría jurídica, el ámbito de protección de la estafa se amplía desmedidamente. En primer lugar, se le reprocha a la tesis de Binding la extensión de la protección a derechos que recaen sobre objetos sin valor dinerario o económi$\mathrm{Co}^{44}$. En efecto, la equiparación de toda forma de derecho subjetivo sin consideración alguna a su contenido económico es algo difícilmente conciliable con las exigencias del tráfico, el cual emplea como criterio orientador fundamental los parámetros del valor económico, de lo cual resulta que "todos los objetos del mercado susceptibles de los más diversos negocios jurídicos son tales precisamente en la medida en que incorporan un valor" 45 (Gallego, 2002, p. 119). Con todo, una consecuencia tan extrema de la teoría jurídica no tendría aplicación en aquellos ordenamientos jurídico-penales donde la penalidad de la estafa se vincula directamente con la cuantía de lo defraudado, como ocurre entre nosotros (Art. $467 \mathrm{CP}$ ), por lo cual, según lo ha entendido tradicionalmente la doctrina nacional, el perjuicio ha de ser susceptible de avaluación pecuniaria ${ }^{46}$.

El concepto jurídico de patrimonio es también excesivamente amplio si se considera que, en cuanto rechaza la consideración de la lesión patrimonial como una afectación del patrimonio en su conjunto, hace imposible apreciar una compensación por la entrada al patrimonio de una contraprestación que, aunque distinta de aquella pactada, sea de valor económico equivalente a lo entregado por quien realiza la disposición patrimonial ${ }^{47}$. Con ello se tiene un concepto puramente formal de perjuicio, pudiendo presentarse la singular paradoja de que, a consecuencia del solo incumplimiento de la obligación, se afirme el perjuicio al mismo tiempo que el sujeto pasivo, en virtud de dicha compensación, pueda incluso ver aumentado su patrimonio al realizar una comparación de este como unidad de valor antes y después de realizar la disposición patrimonial. En último término, esta consideración del patrimonio como una suma de los derechos subjetivos que lo componen (y, en consecuencia, el rechazo del principio de compensación) hace difusa la distinción de los delitos contra los valores patrimoniales según el bien jurídico tutelado en delitos contra el patrimonio en su conjunto (v. gr. la estafa) de aquellos delitos contra bienes patrimoniales concretos (v. gr. el delito de daños, el hurto, la apropiación indebida), identificándose así patrimonio y propiedad ${ }^{48}$.

\footnotetext{
${ }^{44}$ MAURACH (1953) p. 248.

45 Con todo, debe hacerse notar que este mismo autor (p. 332) valora positivamente el énfasis puesto por la teoría jurídica en la propiedad como un valor en sí mismo, con independencia del objeto sobre que recae, considerando que el verdadero inconveniente de la tesis de BINDING radica en la adopción de la noción de derecho subjetivo como único marco de referencia a efecto de determinar el ámbito de protección de la estafa.

46 ETCHEBERRY (1997) p. 399.

47 Maurach (1953) p. 247; Asúa (1993) p. 94; HernándeZ (2003) pp. 171-172. Sobre este punto, GALlego (2002) pp. 119-120, considera esta crítica, en el contexto del ordenamiento jurídico español, válida solo respecto de las obligaciones de dar una especie o cuerpo cierto, así como de las de hacer o no hacer que tengan el carácter de intuito personae, toda vez que el Art. 1096 CC español permite cumplir con la obligación sobre cosa genérica a expensas del deudor, en cuyo caso no podría decirse que existe un perjuicio jurídico en la medida que el mismo ordenamiento jurídico admite tal "compensación".

48 En este sentido ChOCLÁN (2000) p. 57; PASTOR (2004) p. 32. Según esta distinción, en los delitos contra la propiedad el ataque se dirige contra la relación dominical del sujeto con relación a la cosa,
} 
La noción jurídica de patrimonio es también criticado en cuanto importa una fuerte subjetivización de dicho concepto. En efecto, si se observa detenidamente el asunto, se advertirá que la concurrencia del perjuicio se encuentra sujeta a la voluntad del titular del patrimonio, pues de la víctima dependerá excluir la afirmación del perjuicio por el hecho de aceptar la prestación ofrecida distinta de aquella que se debe conforme a derecho ${ }^{49}$. Así, el elemento del perjuicio como resultado típico apreciable en el mundo exterior se hace difuso al hacerlo depender de los gustos y preferencias de la víctima, plasmados en la finalidad subjetiva perseguida por la disposición patrimonial. Según lo expresa Maurach, con estas consideraciones pierde la estafa su carácter de delito patrimonial, castigándose solo la infracción en contra de la buena fe en el tráfico, con lo cual la teoría jurídica, en sus últimas consecuencias, falsea la naturaleza de la estafa ${ }^{50}$.

\section{EL CONCEPTO ECONÓMICO DE PATRIMONIO. EL PATRIMONIO COMO CONJUNTO DE POSICIONES CON VALOR ECONÓMICO}

\subsection{FORMULACIÓN DEL CONCEPTO ECONÓMICO Y SUS ORÍGENES EN LA JURISPRUDENCIA ALEMANA}

Los inconvenientes de que adolece la teoría jurídica del patrimonio determinaron el surgimiento en la doctrina alemana de la llamada teoría económica del patrimonio (wirtschaftliche Vermögenstheorie). Respecto de esta última, es posible encontrar diversas formulaciones. Así, según Dreher y Tröndle, el patrimonio representa la suma de los bienes con valor dinerario de una persona ${ }^{51}$. Krey, por su parte, concibe el patrimonio como la totalidad de los bienes pertenecientes a una persona, sin que sea relevante el que dichos bienes le pertenezcan conforme a derecho o tengan reconocimiento jurídico ${ }^{52}$. Dentro de esta corriente, destaca en la jurisprudencia BGHSt 16, 220, que define el patrimonio como la suma de todos los bienes con valor dinerario una vez descontadas las obligaciones ${ }^{53}$.

mientras que en los delitos patrimoniales propiamente tales el menoscabo se refiere al poder económico del sujeto, lo cual reclama una consideración del patrimonio en cuanto universalidad jurídica. Esta distinción ha conducido a la doctrina alemana a considerar que en los delitos contra la propiedad, a diferencia de los delitos patrimoniales, no es necesario que el objeto material del ataque tenga valor dinerario, conclusión que en España es rechazada, entre otros, por HUERTA (1980) pp. 36-37, ello en consideración a la exigencia del ánimo de lucro en el tipo del hurto en el CP español (como ocurre en nuestro $432 \mathrm{CP}$ ).

49 MaURACH (1953) p. 248; JaKObS (1977) p. 229; HeRnÁNDEZ (2003) p. 173; Asúa (1993) p. 95; GALLEGO (2002) p. 120.

${ }^{50}$ MAURACH (1953) p. 248.

51 DREHER y TRÖNDLE (1991) NM 27: "Vermögen ist der Inbegriff der geldwerten Güter einer Person". Citan estos autores como sustento de la definición que proporcionan la jurisprudencia contenida en BGH 3, 102; 16, 221.

52 KREY (1995) NM 428:

"Vermögen (ist) die Gesamtheit der einer Person zustehenden Güter, wobei es nicht darauf ankommt, ob sie ihr rechtens zustehen und rechtlich anerkannt sind".

53 BGHSt 16, $220=$ NJW 1961, p. 1876. La cita textual es la siguiente: "Die Summe alle geldwerten Güter nach Abzug der Verbindlichkeiten". 
Pese a las pequeñas variantes presentes en las diversas formulaciones que del concepto económico de patrimonio se han ofrecido, todos los autores que adhieren a dicho concepto, según lo pone de relieve Cramer, consideran como incluidas en el patrimonio todas aquellas posiciones a las que es posible atribuir un valor económico, sin tomar en consideración su naturaleza jurídica ${ }^{54}$. De este modo, la pertenencia al patrimonio de los elementos patrimoniales en particular, así como el valor de cada uno de estos, son determinados a partir de criterios puramente económicos ${ }^{55}$.

Según se adelantó, el origen de la teoría económica en la jurisprudencia alemana debe buscarse en dos trascendentales resoluciones del Plenario en lo Penal (vereinigte Strafsenate) del RG, a saber, RGSt 16,1 (sentencia de 20 de abril de 1887), y RGSt 44, 230 (sentencia de 14 de diciembre de 1910) ${ }^{56}$. En la primera de estas resoluciones se acoge expresamente el principio de compensación, afirmándose el perjuicio patrimonial solo en cuanto el valor de la disposición patrimonial efectuada por la víctima supere el de la contraprestación recibida ${ }^{57}$. Con ello se admite que la contraprestación, pese a no corresponderse con lo que la víctima tiene derecho a exigir, tiene un valor para esta, negándose toda concesión a la voluntad subjetiva del sujeto pasivo ${ }^{58}$.

Por su parte, la resolución contenida en RGSt 44, 230 admite el perjuicio patrimonial y condena por estafa a un vendedor que proporcionó a diversas mujeres al precio de diez marcos unos polvos enteramente inocuos cuyo valor de mercado era de treinta o cuarenta centavos, haciéndoles creer a estas que se trataba de una sustancia abortiva. El interés que ofrece esta sentencia radica precisamente en que no resulta relevante al momento de afirmarse por parte del RG la existencia del perjuicio patrimonial el hecho que las víctimas estaban perfectamente advertidas de la naturaleza ilícita del negocio que habían celebrado. Según se advierte, esta resolución importa un distanciamiento respecto de la negativa de la teoría jurídica a extender el ámbito de protección de la estafa aun a los negocios con objeto o causa ilícita. Así, en palabras del mismo RG, el concepto de patrimonio es ante todo un concepto de la vida económica (ein Begriff des wirtschaflichen Lebens), el cual se define como "la suma de los bienes con valor dinerario de una persona" 59 .

\footnotetext{
54 CRAMER (1985) NM 80.

55 CRAMER (1985) NM 80.

56 MaUrach (1953) p. 248; Cramer (1985) NM 80; JAKObS (1977) p. 229. Debe consignarse que, sobre este punto, los autores citados difieren en cuanto a la importancia que debe asignarse a estas dos resoluciones del RG. Mientras MAURACH se refiere a ambas como fundamentales (grundlegend) JAKOBS, por su parte, sostiene de manera enérgica que el quiebre del RG con la tesis jurídica debe situarse, a más tardar, en RGSt 16,1. Debe destacarse que BINDING ([1902] 1969) p. 358 (nota no 1) junto con citar RGSt 16,1, cita otras resoluciones del RG previas a dicha sentencia que aplican el criterio que este autor, desde la perspectiva de su tesis jurídica, llama "el monstruo de la unidad de valor" (das Monstrum des Gesamtwertes). 57 RGSt 16, 1 (5). Reproducida parcialmente por JAKOBS (1977) p. 229. La cita textual es la siguiente: "Diese Wirkungen können einerseits den Wert des Vermögens vermindert, anderseits vergrößsert haben, dann kommt es auf das Verbältnis der Wertverminderung zu der Wertvergrößerung an und ist eine Vermögensbeschädigung (...) nur dann vorhanden, wenn die erstere die letztere im Geldwerte überwiegt".

58 JAKOBS (1977) p. 229.

${ }^{59}$ RGSt 44, 230 (233). Reproducida parcialmente por BLEI (1983) p. 216.
} 


\subsection{CONTENIDO DEL CONCEPTO ECONÓMICO DE PATRIMONIO}

A partir del concepto económico de patrimonio pueden extraerse diversas consecuencias. Ante todo, se pretende superar la estrecha protección jurídico-penal ofrecida por la teoría jurídica. Este propósito se resume en el tan difundido aforismo "no hay patrimonio que no esté protegido en contra de la estafa" ["Es gibt grundsätzlich kein gegen Betrug ungeschütztes Vermögen” ${ }^{60}$. Se apunta así al abandono del aparato conceptual extrapenal del derecho civil condensado en la forma de derechos subjetivos patrimoniales y su reemplazo por consideraciones de orden material relativas a las relaciones del titular del patrimonio con los bienes económicos ${ }^{61}$.

Al tenor de lo anterior, el concepto económico protege en primer lugar los derechos subjetivos patrimoniales, pero, a diferencia de la teoría jurídica, no por el solo hecho de ser tales, sino en cuanto estén dotados de un contenido económico o dinerario. Resultan así excluidos como posibles objetos del delito de estafa aquellos derechos con un mero contenido de afección ${ }^{62}$. Supuesto un contenido económico, resultarán protegidos por el contrario derechos subjetivos tales como la propiedad, créditos, el derecho real de prenda, etc. ${ }^{63}$.

También forman parte del patrimonio aquellas posiciones fácticas económicamente valiosas, pese a que el ordenamiento jurídico no les otorgue reconocimiento bajo la forma de un derecho subjetivo en sentido estricto ${ }^{64}$. Así, la teoría económica entenderá la posesión como comprendida en el patrimonio y, es más, en la versión más pura de dicha doctrina se incluirá también a la posesión de mala fe (unredlicher Besitz) ${ }^{65}$. Como se recordará, ya Binding, pese a negarle la protección jurídico-penal, reconocía a la posesión como perteneciente al patrimonio desde una perspectiva económica ${ }^{66}$.

Otro tanto ocurre con pretensiones nulas (nichtige Forderungen), siempre que contengan un valor económico derivado del hecho de aparecer como posible su cumplimiento desde un punto de vista fáctico, sea por existir relaciones comerciales, de parentesco, de amistad, sociales o cualquiera otra respecto del deudor ${ }^{67}$. También se encuentran comprendidas en el patrimonio a la luz de la teoría en comento las obligaciones naturales, ello en tanto, pese a no ser exigibles desde un punto de vista jurídico, tengan un valor económico ${ }^{68}$.

\footnotetext{
${ }^{60}$ MaUraCH (1953) p. 249; en igual sentido KreY (1995) NM 428. Como ejemplos de jurisprudencia que recoge este aforismo CRAMER (1985) NM 80, hace mención a BGHSt 2, 365, así como BGHSt 8, 256.

61 CRAMER (1985) NM 80.

62 Maurach (1953) p. 249; Dreher y TrÖndle (1991) NM 27a.

${ }^{63}$ LACKNER (1987) p. 1077; DREHER y TRÖNDLE (1991) NM 27a.

${ }^{64}$ BLEI (1983) p. 217.

65 En ese sentido BLEI (1993) p. 218; KREY (1995) NM 436. Como veremos más adelante, esta conclusión es rechazada por algunos autores que, si bien aceptan los puntos de partida de la teoría económica, son partidarios de aplicar al concepto económico correctivos jurídicos. Así CRAMER (1985) NM 94.

${ }^{66}$ BINDING ([1902] 1969) p. 240

67 KREY (1995) NM 430, 438.

68 Así, KREY (1995) NM 437, quien cita la resolución contenida en BGHSt 2, 364; en igual sentido Dreher y Tröndle (1991) NM 27a; MAUrACH (1953) p. 248. En el derecho civil alemán, a diferencia de lo que ocurre entre nosotros (Art. 1470-1472 CC) no existe una regulación legislativa sistemática
} 
El concepto de patrimonio recoge asimismo las expectativas, aun cuando no se encuentren contenidas bajo la forma de un derecho subjetivo ${ }^{69}$. Sin embargo, se advierte en todos los autores que adhieren a la teoría económica un esfuerzo por establecer algunas distinciones en cuanto a la extensión de la protección que debe otorgársele a las expectativas. Se rechaza así a las expectativas generales e indeterminadas y las meras esperanzas como parte integrante del patrimonio ${ }^{70}$.

A efecto de precisar qué tipo de expectativas resultarán protegidas, se han intentado diversas formulaciones. Afirma Blei que es necesario que exista una probabilidad cierta de realización de la expectativa ${ }^{71}$. Dreher y Tröndle, por su parte, sostienen que puede constatarse un perjuicio en los supuestos de frustración de un incremento patrimonial que con probabilidad se espera ${ }^{72}$. Krey, por último, considera como pertenecientes al patrimonio aquellas expectativas respecto de las cuales no existe un derecho cuando se presenta una probabilidad bastante de incremento patrimonial ${ }^{73}$.

Al momento de tratar las expectativas, los autores que sustentan la teoría económica prestan especial atención a la clientela. Se considera la clientela ya existente de un industrial, un comerciante o de un profesional liberal como una forma de expectativa perteneciente al patrimonio. Sin embargo y tal como se afirma respecto de toda expectativa en general, para que se otorgue protección jurídico-penal es necesario que la clientela alcance un cierto grado de consolidación o de estabilidad ${ }^{74}$.

Respecto del problema de si la protección del tipo de la estafa comprende el ámbito de los negocios inmorales o ilícitos, los partidarios del concepto económico se pronuncian afirmativamente ${ }^{75}$. Se admitirá de este modo, por ejemplo, el perjuicio en el supuesto de la víctima que resulta engañada por medio de una falsa oferta relativa a favores sexuales, en virtud de la cual ha realizado por adelantado un pago a una prostituta o a un alcahuete. Este supuesto es el contenido en la sentencia del OLG Köln de 11 de abril de 1972 , en la cual se condena en virtud del $\$ 263$ StGB (estafa) a un sujeto que obtuvo de un inmigrante turco la suma de 15 marcos a cambio de conseguirle una mujer, negándose posteriormente a cumplir con lo acordado o devolver la suma recibi-

\footnotetext{
de las obligaciones naturales (Naturalobligationen) pero suelen citarse como ejemplos, entre otros, las deudas provenientes del juego y la apuesta $(\$ 762$ BGB) así como el contrato de agencia o corretaje matrimonial (Ehemaklervertrag, $\$ 656$ BGB) supuestos en los cuales nos encontramos ante pretensiones que carecen de acción para exigir su cumplimiento, pero que, cumplidas voluntariamente, no dan derecho a repetición. Sobre las obligaciones naturales en el derecho civil alemán, vid. VON TUHR (19101918) pp. 148-149; ENNECCERUS et al. (1948) p. 12 ss. ; HEDEMANN (1958) p. 80; LOEWENWARTER (1935) p. 115.

${ }^{69}$ Blei (1983) p. 218; Dreher y Tröndle (1991) NM 28; Krey (1995) NM 440; JaGUSCH (1958) p. 449.

70 BLEI (1983) p. 218; DREHER y TRÖNDLE (1991) NM 28.

${ }^{71}$ BLEI (1983) p. 218: "es muß (...) eine gewisse Wahrscheinlichkeit der Realisierung einer Exspektanz eingetreten sein".

72 DREHER y TRÖNDLE (1991) NM 28. Citan estos autores en apoyo de esta formulación la jurisprudencia contenida en BGHSt 2, 367; 17, 147.

${ }^{73}$ KREY (1995) NM 440: "Anwartschaften, bei denen noch kein Rechtsanspruch besteht, gehören zum Vermögen, wenn schon eine hinreichende Wahrscheinlichkeit der Vermögensmehrung vorliegt".

${ }^{74}$ BLEI (1983) p. 219; DREHER y TRÖNDLE (1991) NM 28.

75 Dreher y Tröndle (1991) NM 29; Krey (1995) NM 429.
} 
$\mathrm{da}^{76}$. La sentencia expresamente rechaza el concepto de "patrimonio jurídicamente protegido" (rechtlich geschütztes Vermögen) y atiende a un criterio exclusivamente económico a efecto de constatar el perjuicio sufrido por la víctima.

En consonancia con lo anterior, Krey dirá incluso que el patrimonio en el sentido del $\$ 263$ StGB comprende no solo la posesión de bienes adquiridos de manera inmoral o contraria a la ley, sino también la posesión adquirida a través de acciones penalmente punibles ${ }^{77}$. Así, resulta concebible la estafa al ladrón respecto de bienes hurtados o la estafa en contra del estafador ${ }^{78}$. Krey proporciona dos argumentos a favor de esta interpretación económica pura ${ }^{79}$. En primer lugar, hace presente la necesidad de una interpretación sistemática del StGB, en cuanto, en el derecho penal alemán, los tipos del hurto $(\$ 242)$ y del robo $(\$ 249)$, según afirma, pueden satisfacerse en el supuesto en que un sujeto hurta o roba el botín previamente hurtado o robado por un tercero. Si los tipos del hurto y del robo, sostiene Krey, amparan bienes adquiridos a través de acciones prohibidas por el derecho e, incluso, penalmente punibles, razones tendientes a asegurar la unidad del ordenamiento punitivo aconsejan que el patrimonio, para efectos del $\$ 263$ StGB, comprenda también dichos supuestos.

En segundo lugar, Krey esgrime un argumento de naturaleza político-criminal. Sostiene este autor que la afirmación de la validez del ordenamiento jurídico-penal (en particular el $\$ 263$ StGB y otros tipos penales que señala) aun a efecto de proteger elementos integrantes del patrimonio obtenidos de un modo inmoral o prohibido por el derecho sirve al propósito de obtener la paz jurídica. De lo contrario, afirma Krey, se estará otorgando aprobación a la estafa al interior de las relaciones de aquellos sujetos que se comportan de modo contrario a las prescripciones del derecho. Como se advierte, este argumento apunta a evitar la configuración de un ámbito entregado exclusivamente a la autotutela de cada sujeto, en otras palabras, de un espacio libre del derecho.

Por último, un elemento habitualmente señalado por los partidarios de la teoría económica como perteneciente al patrimonio es la fuerza de trabajo o, como lo precisa Krey, la posibilidad de aprovechamiento económico de esta ${ }^{80}$. Este mismo autor afirmará que, desde una perspectiva puramente económica, solo resulta relevante si la fuerza de trabajo en el contexto de una disposición patrimonial conduce habitualmente en la vida económica a una contraprestación ${ }^{81}$. Consiguientemente y de modo coherente con lo que expone a propósito del perjuicio en los negocios ilícitos, los servicios prestados por una prostituta constituyen para este autor un valor patrimonial en el sentido del tipo de la estafa y tendrán eventualmente el carácter de una disposición patrimonial ${ }^{82}$.

\footnotetext{
76 OLG Köln NJW 1972, p. 1823.

77 KREY (1995) 429.

78 Respectivamente, RGSt 44, 232; RGSt 65, 3. Cit. por Dreher y TrÖNDLE (1991) NM 29.

79 Para lo que sigue, cfr. KreY (1995) NM 433-435.

${ }^{80}$ KREY (1995) NM 439.

${ }^{81}$ KREY (1995) NM 439.

${ }^{82}$ KREY (1995) NM 439. En igual sentido DreHER y TrÖNDlE (1991) NM 29.
} 


\subsection{CONFIGURACIÓN DEL PERJUICIO PATRIMONIAL A LA LUZ DEL CONCEPTO ECONÓMICO}

Al momento de constatar el perjuicio patrimonial, la teoría económica tiene en consideración el patrimonio como una unidad de valor. Por consiguiente, el perjuicio se afirma por la constatación de la disminución del saldo contable relativa al patrimonio considerado en su conjunto. Se trata así de una diferencia negativa entre el valor del patrimonio antes y después de la disposición patrimonial de la víctima ${ }^{83}$. Desde un punto de vista económico, la estafa no protege el patrimonio ante la pérdida de uno o más de sus elementos particulares en cuanto tales, como es el caso de la teoría jurídica, sino frente a la disminución del valor económico del patrimonio como un todo ${ }^{84}$.

Al tenor de lo anterior, la teoría económica pone especial énfasis en observar el principio de compensación, en lo que al ámbito de los negocios bilaterales se refiere. Bajo este punto de vista, la pérdida de un elemento patrimonial conduce a un perjuicio solo cuando no resulte compensada por la entrada en el patrimonio de una posición de valor económico equivalente ${ }^{85}$. Esto ha sido reafirmado recientemente por el $\mathrm{BGH}$ al sostener que, "para la prueba de un perjuicio patrimonial en el sentido del tipo de la estafa, lo decisivo es solamente la comparación de valor entre prestación y contraprestación desde un punto de vista económico" 86.

Para comprender mejor lo anterior, resulta relevante detenerse en algunos ejemplos de la jurisprudencia alemana, la cual ha vuelto reiteradamente sobre el problema de la compensación. En primer lugar, un caso clásico de amplia repercusión en la doctrina de dicho país es la resolución contenida en BGHSt 16, 22087. En esta sentencia el supuesto de hecho consistía en que un sujeto dedicado al negocio textil ofrece para la venta a través de un periódico pantalones de lana pura al precio de 26 marcos. El sujeto vendió un par a este precio, reiterándole al comprador de manera verbal que la tela estaba compuesta de lana pura, cuando en verdad el material de fabricación era viscosilla, hecho conocido por el autor. Debe tenerse en cuenta que los pantalones fueron vendidos al precio usual de mercado para el material a partir del cual efectivamente habían sido confeccionados ${ }^{88}$.

A partir de los hechos descritos, el BGH no constató un perjuicio patrimonial típico, sosteniendo que es preciso comparar las prestaciones recíprocas de las partes del contrato, resultando la víctima perjudicada solo en tanto el valor de su prestación no resulta compensada por la de su contraparte. Por el contrario, si resultan compensadas solo podrá decirse que el patrimonio de quien ha sufrido el engaño ha experi-

\footnotetext{
83 Dreher y Tröndle (1991) NM 30; MAUraCH (1953) p. 250; Blei (1983) p. 231; LACKNER, (1987) p. 1078; SAMSON y GÜNTHER (1996) NM 127.

84 SAMSON y'GÜNTHER (1996) NM 127.

85 SAMSON y'GÜNTHER (1996) NM 127; en igual sentido DREHER y'TRÖNDLE (1991) NM 30.

86 BGHSt 47, 1 (Sentencia de 26 de abril de 2001). En términos similares KrEY (1995) NM 445.

${ }^{87}=$ NJW 1961, pp. 1876 ss. Los comentarios a esta resolución de JAKOBS (1977) pp. 229 ss.

${ }^{88} \mathrm{La}$ interesante variante de los hechos aquí planteados propuesta por GÖSSEL (1996) NM 169, quien sostiene que, desde una perspectiva objetivo-individual, el perjuicio debió haberse afirmado si la víctima hubiera sido alérgica al material real de fabricación de los pantalones.
} 
mentado una modificación de sus elementos integrantes, pero su valor permanecerá inalterado ${ }^{89}$. El fallo se pronuncia expresamente en contra de la sentencia del OLG Köln NJW 1959, 1980, sosteniendo que para el tipo de la estafa no es suficiente que la prestación del vendedor carezca de la cualidad falsamente asegurada ${ }^{90}$. En ese sentido, reitera que la estafa no puede ser considerada como un delito contra la verdad y la buena fe en el tráfico, sino que tiene la naturaleza de un delito patrimonial ${ }^{91}$. Es así que señala que "el valor de un patrimonio no es determinado por las apreciaciones personales de su titular" 92 .

En la línea anterior, de gran interés es también la sentencia del OLG Köln de 23 de enero de $1979^{93}$. Ante dicho tribunal se presentó el caso de un vendedor de suscripciones de revistas, quien le aseguró falsamente a la víctima que había sido liberado recientemente luego de una condena relacionada con estupefacientes y que las ganancias netas de cada suscripción anual de revistas que vendiera estarían destinadas al beneficio de otros condenados por delitos de igual naturaleza. En atención a estas consideraciones, la víctima decidió comprar una suscripción de revistas, las cuales eran de amplia circulación y le fueron ofrecidas por un precio que era el habitual de mercado.

En el caso propuesto, el tribunal se decidió por la absolución del acusado, toda vez que consideró que faltaba el perjuicio patrimonial propio del tipo de la estafa ${ }^{94}$. Se sostiene que no basta para la afirmación del perjuicio el hecho que la víctima haya hecho una disposición patrimonial que no habría realizado de conocer las circunstancias reales, toda vez que el tipo de la estafa no protege la libertad de disponer del propio patrimonio según las preferencias personales ${ }^{95}$. Desde un punto de vista económico-objetivo, las prestaciones recíprocas resultan compensadas ${ }^{96}$. Con lo anterior se desestima la relevancia del fin social que se propuso la víctima al momento de realizar la disposición patrimonial ${ }^{97}$.

\footnotetext{
89 BGHSt 16, 220.

90 BGHSt 16, 220.

${ }^{91}$ BGHSt 16, 220.

92 BGHSt 16, 220.
}

(La traducción es nuestra). Sin embargo, es de suma relevancia destacar que la sentencia, pese a negar los criterios puramente subjetivos para determinar el perjuicio patrimonial, se adhiere, sin abandonar una óptica económica, a criterios objetivo-individuales, sobre los que volveremos con detalle más adelante.

93 OLG Köln, NJW 1979, p. 1419.

94 Sin embargo, en un supuesto de hecho muy similar, la sentencia contenida en OLG Düsseldorf NJW 1990, p. 2397 se decide por la condena. En este caso la víctima compró una suscripción a una revista motivada exclusivamente por la afirmación mendaz del vendedor relativa a que las ganancias serían destinadas a una institución dedicada al cuidado de personas ancianas. Como se advierte, el OLG Düsseldorf, de manera contraria a la tendencia jurisprudencial general, consideró como relevante la frustación del fin social propuesto por la víctima.

95 OLG Köln, NJW 1979, p. 1419 (1420).

96 OLG Köln, NJW 1979.

97 Con todo, tal como lo hicimos presente respecto de BGHSt 16, 220, la sentencia en comento también apela a la necesidad de aplicar criterios individualizadores de naturaleza objetiva, según el parecer de un tercero imparcial. Así, se le da relevancia a que, según constaba en la causa, la víctima, junto con el fin social principal, consideró el hecho que ella misma adquiría ocasional o regularmente revistas semejantes, por lo que la compensación entre las prestaciones debía incluir la utilidad que le reportaba lo recibido. 
El OLG de Karlsruhe, por su parte, en su resolución de 4 de enero de 1980 se pronuncia también sobre el problema de la compensación ${ }^{98}$. El supuesto de hecho consistía en que el acusado había comprado previamente un vehículo de segunda mano por la suma de 24.500 marcos. Este vehículo había sufrido graves daños debido a un accidente, lo cual exigió reparaciones que ascendieron a la suma de 10.000 marcos. Este hecho era conocido por el acusado, quien vendió el vehículo por la suma de 23.500, incluyéndose en el contrato de compraventa una cláusula en la que se hacía constar que el automóvil no había sufrido accidente alguno.

La resolución del OLG de Karlsruhe, en consonancia con la jurisprudencia antes citada, reitera que "el tipo (de la estafa) presupone que el patrimonio se ve disminuido en su valor económico por la disposición patrimonial de quien ha sido víctima del engaño, sin que dicho menoscabo se vea plenamente compensada por un incremento inmediato" 99. Luego agrega que "solo cuando ha sido determinado el valor de mercado del objeto vendido puede efectuarse la comparación entre este y la contraprestación y con ello dar respuesta a la pregunta relativa a si se ha producido o no un perjuicio patrimonial desde una perspectiva objetiva abstracta" ${ }^{100}$. La sentencia considera irrelevante el hecho que la víctima no hubiera comprado el vehículo por el precio acordado de haber tenido conocimiento de los daños causados por el accidente ${ }^{101}$. En virtud de las consideraciones señaladas, negó el tribunal la existencia de perjuicio en el caso sometido a su decisión.

Como es posible advertir, de la jurisprudencia examinada se desprende una tendencia a desestimar toda consideración relativa a las representaciones y fines puramente subjetivos de la víctima a efecto de determinar un perjuicio penalmente relevante. Por el contrario, lo decisivo será una avaluación desde la perspectiva del valor económico de las prestaciones sinalagmáticas, con lo cual, de resultar estas compensadas, se seguirá la exclusión del perjuicio. Al tenor de estas consideraciones, no se le asignará relevancia al engaño recaído sobre una cualidad del objeto recibido, en tanto el valor económico objetivo de este se encuentre contenido en el precio pagado ${ }^{102}$.

Otro punto de especial relevancia en relación con la constatación del perjuicio es el referido a los supuestos de puesta en peligro del patrimonio ${ }^{103}$. Sobre este punto, desde la perspectiva de la teoría económica, “también la puesta en peligro de un elemento particular del patrimonio puede tener como consecuencia la disminución del patrimonio en su conjunto" (Dreher y Tröndle, 1991, NM 31) ${ }^{104}$. Sin embargo, para que pueda admitirse esta afirmación, los partidarios del concepto económico no consideran suficiente la mera posibilidad de un peligro, sino que exigen la concurrencia de un

\footnotetext{
98 OLG Karlsruhe, NJW 1980, p. 1762.

99 Olg Karlsruhe, NJW 1980, p. 1762 (La traducción es nuestra).

100 OLG Karlsruhe, NJW 1980, p. 1762.

101 OLG Karlsruhe, NJW 1980, p. 1762.

102 Gallego (2002) p. 340.

103 Un completo panorama sobre este punto puede encontrarse en GaLlego (2002) pp. 386 ss. Vid. también BALMACEDA y PRELler (2006) pp. 185-217.

${ }^{104}$ La traducción es nuestra.
} 
peligro concreto ${ }^{105}$. Así, por ejemplo, la suscripción de un pagaré obtenida engañosamente en consideración a una obligación inexistente constituirá ya un peligro concreto respecto del patrimonio y un perjuicio en el sentido del tipo de la estafa, toda vez que dicha puesta en peligro importa de suyo un patrimonio más gravado y, por consiguiente, una merma de su valor total desde un punto de vista económico y contable ${ }^{106}$.

\subsection{CRÍTICAS}

En contra de la teoría económico en su concepción extrema se han planteado diversas objeciones. Ante todo, la aplicación de criterios exclusivamente económicos al momento de fijar un concepto de patrimonio no hace más que repetir la remisión total a parámetros extrapenales que se le reprochaba a la teoría jurídica, solo que en este caso dicha remisión se dirige no hacia el derecho civil, sino al sistema económico ${ }^{107}$. Al apelar exclusivamente a consideraciones de hecho, rechazando de paso todo tipo de criterios normativos, la teoría económica pura se transforma en lo que Cramer ha calificado como un "positivismo fáctico" (Tatsachenpositivismus) ${ }^{108}$.

Pese a lo anterior, al momento de delimitar los contornos de un patrimonio concreto, determinando la pertenencia a este de objetos en particular, la teoría económica se ve compelida a acudir a parámetros jurídico-normativos, revelándose así la insuficiencia de criterios exclusivamente económicos para los efectos de satisfacer dicho propósito ${ }^{109}$. Se encuentra en lo cierto Gallego al señalar que el aforismo relativo a que no hay patrimonio que no esté protegido en contra de la estafa es manifiestamente tautológico, toda vez que lo mismo entendía la teoría jurídica; el punto es qué contenido se le dará al concepto de patrimonio, para lo cual dicha fórmula no proporciona utilidad interpretativa alguna ${ }^{110}$.

Un aspecto especialmente problemático de la teoría extrema es aquel relativo al tratamiento que esta le otorga a las posiciones económicas en el contexto de negocios inmorales o ilícitos. En este punto, la extensión que se le concede a la protección jurídico-penal del tipo de la estafa resulta excesivamente amplia. En efecto, como ha quedado ya de manifiesto, la teoría económica le otorga protección a posiciones adquiridas de manera inmoral o ilícita e incluso a través de acciones penalmente punibles.

A partir de lo anterior, se ha señalado que la teoría económica pura implica la introducción de intolerables contradicciones valorativas respecto de las demás ramas del derecho, lo cual conduce a un quebrantamiento del principio de la unidad del ordena-

\footnotetext{
105 Dreher y TrÖNDle (1991) NM 31; KREY (1995) NM 448. Cita este último autor en este sentido las resoluciones contenidas en BGHSt 21, 112; BGH JZ 1988, 419 ss.

106 KREY (1995) NM 448, nota 221.

107 PASTOR (2004) p. 37.

108 CRAMER (1985) NM 80.

109 PASTOR (2004) p. 37; GALLEGO (2002) pp. 139-140. Este último autor destaca como RGSt 44, 230, resolución paradigmática dentro de la concepción económica extrema, admite la necesidad de acudir a las disposiciones del derecho civil a efecto de determinar la pertenencia de un bien económico a una persona en concreto.

110 GaLlego (2002) pp. 131-132.
} 
miento jurídico ${ }^{111}$. Ello en cuanto, de aceptarse los presupuestos del concepto económico extremo, el derecho penal dispensaría protección a posiciones que otras ramas no consideran dignas de protección o que incluso son reprobadas expresamente. Así, para el derecho penal carecería de significado la nulidad con la que el derecho civil sanciona aquellos negocios jurídicos con un objeto prohibido por las leyes o contrario a las buenas costumbres (Arts. 1461 y 1466 CC; $\$ \$ 134$ y 138 BGB). Ante dicha posibilidad, la jurisprudencia más reciente del $\mathrm{BGH}$ ha excluido del concepto jurídico-penal de patrimonio aquellas prestaciones que sirven a fines prohibidos o inmorales, señalándose expresamente que, de lo contrario, se pondría al derecho penal en contradicción con el resto del ordenamiento jurídico ${ }^{112}$.

Por último, cabe consignar que la teoría económica ha sido objeto de numerosas críticas desde la perspectiva de aquellos autores que reclaman una mayor individualización del concepto de patrimonio en relación con su titular, toda vez que al aplicar exclusivamente criterios económicos objetivos y abstractos, basados en el principio de la compensación, se desatenderían por completo los fines y necesidades personales de la víctima ${ }^{113}$.

\section{EL CONCEPTO MIXTO O JURÍDICO-ECONÓMICO DE PATRIMONIO}

\subsection{FORMULACIÓN DEL CONCEPTO JURÍDICO-ECONÓMICO DE PATRIMONIO}

Las graves contradicciones valorativas a las que conduce la teoría económica extrema del patrimonio hicieron patente la necesidad de acudir a correctivos normativos que, partiendo también de un criterio económico, aseguraran al mismo tiempo la vigencia del principio de la unidad del ordenamiento jurídico. Surge así la llamada teoría mixta o jurídico-económica del patrimonio, hoy dominante en la doctrina alemana, así como en la española. Con todo, las diversas formulaciones que del concepto mixto se han ofrecido solo coinciden en este diagnóstico inicial, pero difieren notablemente al momento de fijar el contenido del correctivo normativo que se ha de aplicar ${ }^{114}$.

Las diversas variantes de la teoría jurídico-económica pueden clasificarse en tres grandes grupos ${ }^{115}$. En primer lugar se encuentran aquellas tesis que consideran protegidas por el concepto penal de patrimonio todas aquellas posiciones con valor económico condensadas en la forma de derechos subjetivos. Esta es la postura adoptada por Gallas ${ }^{116}$. Este concepto ha sido con justa razón severamente criticado, toda vez que le es aplicable la misma objeción que formulamos respecto de la teoría jurídica, relativa a que el ámbito de protección resulta excesivamente estrecho, pues excluye posiciones econó-

\footnotetext{
111 Cramer (1985) NM 80; SAMSOn y GÜNTHer (1996) NM 111; LACKNER (1987) p. 1078; GÖSSEL (1996) NM 100; PASTOR (2002) p. 37.

112 BGH NStZ 1987, p. 407.

113 OTTO (1995) pp. 224 ss. Para mayores detalles sobre este punto, SCHLACK (2007) pp. 133-146.

114 En este sentido GÖSSEL (1996) NM 110.

115 Otras clasificaciones de las tesis mixtas, ligeramente diferentes a la que aquí proponemos, pueden encontrarse en SAMSON y GÜNTHER (1996) NM 105; GÖSSEL (1996) NM 111 ss.

116 GALlas (1961) p. 408.
} 
micas de incuestionable relevancia para el tráfico por el solo hecho de no expresarse en un derecho subjetivo ${ }^{117}$.

En segundo lugar podemos encontrar aquellas formulaciones que exigen que las posiciones económicamente valiosas gocen de la protección del ordenamiento jurídico a efecto de considerarlas parte del concepto penal de patrimonio. Es el caso de Welzel, quien, haciendo suyo el concepto contenido en RGSt 66, 285, entiende por patrimonio "la suma de los valores económicos que alguien tiene a su disposición bajo la protección del ordenamiento jurídico" (Welzel, 1967, p. 351)118. También considera necesaria la protección del ordenamiento jurídico Wessels, quien le da a esta concepción el nombre de "concepto económico de patrimonio sobre bases normativas" (wirtschaftlicher Vermögensbegriff auf normativer Grundlage) ${ }^{119}$.

Por último, tenemos aquellas variantes que consideran suficiente que la posición de que se trate tenga la aprobación del ordenamiento jurídico o que, al menos, no sea desaprobada por este. Es así que, según la formulación de Cramer, el patrimonio comprende "todos aquellos bienes con valor económico que una persona tiene bajo la aprobación del derecho de los bienes" (Cramer, 1985, NM 82) ${ }^{120}$. Por su parte, Gössel concibe el patrimonio como el conjunto de bienes con valor dinerario que una persona tiene sin la desaprobación por parte del ordenamiento jurídico-civil ${ }^{121}$. En términos muy similares a este último autor, Kolrausch y Lange también ponen el acento en la falta de desaprobación jurídica ${ }^{122}$.

La adopción de alguna de las variantes anteriormente señaladas no es indiferente en cuanto a sus consecuencias ni se trata de una cuestión meramente nominal o terminológica. Como tendremos ocasión de comprobar, las diversas formulaciones del concepto jurídico-económico conducen a soluciones diferenciadas al momento de fijar los elementos integrantes del patrimonio.

\subsection{CONTENIDO DEL CONCEPTO JURÍDICO-ECONÓMICO DE PATRIMONIO}

En primer lugar, pertenecen al patrimonio desde una óptica jurídico-económica los derechos subjetivos, en tanto estén dotados de valor económico de cambio ${ }^{123}$. Aclara Welzel que el valor económico (wirtschaftlicher Wert) no se ha de entender necesaria-

\footnotetext{
117 SAMSON y GÜNTHER (1996) NM 115; GÖSSEL (1996) NM 111; ASÚA (1993) p. 101 (nota 76).

118 La tradución es nuestra. La cita textual es la siguiente: "Vermögen ist die Summe der jemandem unter dem Schutze der Rechtsordnung zu Gebote stehenden wirtschaflichen Werte”.

119 Wessels (1996) NM 518. Una postura en esta línea ha sido también defendida en la doctrina italiana por FIANDACA y MUSCO (2000) p. 25, quienes apelan a la fórmula del reconocimiento expreso por parte del ordenamiento jurídico.

${ }^{120}$ La traducción es nuestra. La cita textual es la siguiente: "alle wirtschaftlich wertvollen Güter, die eine Person unter Billigung der rechtlichen Güterzuordnung innehat”. Cabe consignar que una formulación diversa puede encontrarse en CRAMER (1966) pp. 472-477, donde el patrimonio se configura a partir no de la aprobación del ordenamiento, sino en la falta de desaprobación.

121 GÖSSEL (1996) NM 121.

122 Kolrausch y Lange (1961) p. 579.

123 Cramer (1985) NM 85; SAMSON y GÜNTHER (1996) NM 118; GÖSSEL (1996) NM 123; WELZEL (1967) p. 351.
} 
mente como equivalente al concepto de valor dinerario (Geldeswert), toda vez que el valor del dinero depende en gran medida de su poder de compra ${ }^{124}$. La protección de los derechos subjetivos comprenderá tanto los créditos como los derechos reales y, en opinión de Cramer, puede eventualmente extenderse también a derechos de familia con un contenido económico (relaciones patrimoniales basadas en el matrimonio, el derecho legal de goce de quien ejerce la patria potestad, etc. $)^{125}$. Desde la perspectiva de aquellas tesis mixtas más restrictivas, solo resultan comprendidas en el concepto jurídico-penal de patrimonio aquellas posiciones económicas contenidas en derechos subjetivos, por lo que se excluirán otros elementos a los que seguidamente nos referiremos, como las expectativas y las pretensiones nulas ${ }^{126}$.

También constituye un elemento del patrimonio la posesión. A diferencia de la tesis económica extrema, las concepciones mixtas limitan el ámbito de protección del tipo de la estafa a la posesión de buena fe, sea que esta se ejerza el poseedor por sí mismo (unmittelbarer Besitz) o por medio de otro (mittelbarer Besitz) ${ }^{127}$. Respecto de este punto, el concepto jurídico-económico construido a partir de la fórmula "protección del ordenamiento jurídico" será aún más restrictivo, resultando comprendida en el patrimonio solo aquella posesión que procede de justo título (rechtmäßiger Besi$t z)^{128}$. A esto replica Cramer que el mismo ordenamiento jurídico-civil alemán otorga protección a ciertos supuestos de posesión de buena fe aun a falta de justo título $(\$ 823 \mathrm{BGB})^{129}$. En consecuencia, para las tesis mixtas más amplias, solo la posesión obtenida de mala fe o, más aún, de un modo delictivo, ha de resultar excluida del concepto de patrimonio del tipo penal de la estafa ${ }^{130}$. Así, por ejemplo, no será concebible la estafa en contra del ladrón respecto de las cosas hurtadas o robadas, como tampoco respecto del receptador ${ }^{131}$.

Integran de igual modo el patrimonio tanto para la fórmula de la protección como para el criterio de la falta de desaprobación aquellas posiciones que en la vida económica se encuentran dotadas de un valor dinerario, no obstante no encontrarse expresadas en un derecho subjetivo, como lo sería, por ejemplo, el goodwill de una

\footnotetext{
124 WELZEL (1967) p. 351.

125 CrAmer (1985) NM 85. Coincidencia en este punto encontramos en la doctrina nacional en DAVIS (1942) p. 65; así como en CONTRERAS (1966) p. 76.

126 GALLAS (1961) pp. 411 ss.

127 CRAMER (1985) NM 94.

128 WELZEL (1967) p. 352.

129 CRAMER (1985) NM 94. Algo similar podría afirmarse para nuestro ordenamiento jurídico-civil, toda vez que el Art. 918 CC no ha limitado la legitimación activa respecto de las acciones posesorias solo al poseedor regular. Sobre este punto, ALESSANDRI et al. (1957) p. 859.

130 CRAMER (1985) NM 94.

131 Una posición divergente sostiene en la doctrina española BAJO (2004) p. 89, quien, pese a sostener un concepto jurídico-económico, acepta de modo general la protección penal del tipo de la estafa respecto de la posesión antijurídica. Ello se explica a partir de la fórmula que proporciona de patrimonio relativa a la apariencia de conformidad al ordenamiento jurídico (p. 22) la cual ha impugnado PASTOR (2004) p. 39, toda vez que no sería suficiente para salvar las contradicciones valorativas, ya que lo "aparentemente jurídico” puede no serlo en verdad. Sobre este punto también MUÑOZ CONDE (2004) p. 433.
} 
empresa o de un estudio jurídico ${ }^{132}$, así como el know-how económico y técnico de un especialista en materias tributarias ${ }^{133}$. Otro tanto ocurre con aquellas pretensiones jurídicas que no dan derecho para exigir su cumplimiento (obligaciones naturales), ello en tanto tengan un valor desde un punto de vista económico, lo cual ocurrirá toda vez que dicho valor sea realizable desde un punto de vista fáctico ${ }^{134}$.

Son también elementos del patrimonio las expectativas de un aumento patrimonial económicamente cuantificable contenidas en una pretensión jurídica ${ }^{135}$. Así, resultarán protegidas por el concepto penal de patrimonio aquellas expectativas de adquisición de un derecho jurídicamente protegidas (Antwartschaftsrecht ${ }^{136}$. El ejemplo más evidente de esto último en el derecho civil alemán es la adquisición de un bien en la cual el vendedor se reserva el dominio hasta el total pago del precio (Eigentumsvorbehalt), existiendo para el comprador una pretensión jurídicamente tutelada de adquisición del dominio ${ }^{137}$.

Pero no solo se integrarán en el patrimonio desde una óptica jurídico-económica las expectativas contenidas en una pretensión jurídica. Por el contrario, excepto por las formulaciones más restringidas, también se entenderán comprendidas las expectativas fácticas (Exspektanzen) ${ }^{138}$. Sin embargo y tal como dijimos a propósito del concepto económico puro, es necesario que la expectativa de que se trate cumpla con ciertos requisitos a efecto de poder ser considerada como un elemento patrimonial. Así, deberá tratarse de una expectativa rodeada de circunstancias tales que permitan esperar con probabilidad un aumento patrimonial, resultando de este modo excluidas del concepto de patrimonio las expectativas y esperanzas generales e indeterminadas ${ }^{139}$. La expectativa en cuestión debe alcanzar un cierto grado de concreción a partir del cual sea posible atribuirle desde ya un valor económico por parte del tráfico negocial, lo cual ocurrirá precisamente toda vez que, según el curso normal de los acontecimientos, se espere con probabilidad suficiente un aumento patrimonial ${ }^{140}$.

Sin embargo, como lo han puesto de relieve Samson y Günther, es en el ámbito de las expectativas, así como en el de las pretensiones nulas, que la teoría jurídicaeconómica anota sus diferencias más evidentes con el baremo económico extremo ${ }^{141}$. Señalan así estos autores que para considerar las expectativas como parte del concepto jurídico-penal de patrimonio protegido, junto con los requisitos de certeza y determina-

\footnotetext{
132 GÖSSEL (1996) NM 123.

133 SAMSON y GÜNTHER (1996) NM 116.

134 SAMSON y GÜNTHER (1996) NM 119; en términos similares se pronuncian CRAMER (1985) NM 91; GÖSSEL (1996) NM 123; WELZEL (1967) p. 351; KOLRAUSCH y LANGE (1961) p. 579.

135 Cramer (1985) NM 86; SAMSON y GÜNTHER (1996) NM 118.

136 Para una definición del concepto de Antwartschaftsrecht desde una perspectiva jurídico-civil, vid. BGH NJW 1955, p. 54.

137 CrAmer (1985) NM 86. Un ejemplo análogo en nuestro ordenamiento sería el derecho personal que nace para quien celebra un contrato de promesa (Art. 1554 CC) para exigir de la contraparte la celebración del contrato prometido.

138 Cramer (1985) NM 87; SAMSOn y GÜNTHer (1996) NM 121; Wessels (1996) NM 518; WelZEL (1967) p. 351.

139 CrAmer (1985) NM 87; en igual sentido SAMSON y GÜNTHER (1996) NM 121.

140 Cramer (1985) NM 87; SAMSON y GÜNTHER (1996) NM 121.

141 SAMSON y GÜNTHER (1996) NM 105.
} 
ción, es preciso que el valor económico de dichas expectativas pueda ser realizado a través de un negocio jurídico de cambio aprobado por el ordenamiento jurídico ${ }^{142}$.

Un especial examen merecen los supuestos relativos a expectativas resueltos por la jurisprudencia alemana. En primer lugar, suele aceptar esta a la clientela con un cierto grado de consolidación como un elemento patrimonial ${ }^{143}$. También se ha considerado como protegido por el tipo de la estafa la expectativa que tiene una persona de arrendar un bien raíz del cual es propietaria ${ }^{144}$, así como la expectativa de adquisición de acciones que tiene un círculo de personas privilegiado por motivos sociales en el contexto de la privatización de una empresa ${ }^{145}$. Sin embargo, constituyen probablemente los casos de mayor interés aquellos en que, en el contexto de un concurso público, se considera como parte integrante del patrimonio la expectativa que, sobre la base de lo conveniente de su oferta, tiene la víctima de obtener la adjudicación en cuestión ${ }^{146}$. Un criterio similar se aplica a la postulación a un puesto de trabajo ${ }^{147}$. En estos supuestos, la jurisprudencia alemana ha constatado el delito de estafa cuando la víctima es inducida a través de engaño a retirar su propuesta o postulación, teniendo el sujeto activo por propósito eliminar la competencia.

En lo que respecta a las obligaciones nulas, las teorías jurídico-económicas alcanzan también resultados diversos a los postulados por el concepto económico puro. A diferencia de este, los partidarios de las tesis mixtas rechazan una aceptación amplia de las obligaciones nulas como elementos patrimoniales. Sin embargo, sobre este punto las diversas formulaciones del concepto jurídico-económico proponen soluciones diferenciadas. Así, aquellos autores que apelan al criterio de la protección del ordenamiento jurídico rechazan de modo general la posibilidad de constatar el delito de estafa respecto de obligaciones nulas ${ }^{148}$.

\footnotetext{
142 SAMSON y GÜNTHER (1996) NM 116.

143 RGSt 71, 334; 74, 316. Referencias tomadas de SAMSON y GÜNTHER (1996) NM 122. Cabe consignar que ANTÓN ONECA (1957) p. 13, uno de los más destacados representantes de las tesis jurídico-económicas en la doctrina española es más restrictivo en este punto que lo sostenido por la generalidad de la doctrina y la jurisprudencia alemanas, toda vez que exige para afirmar el perjuicio patrimonial que la clientela sustraída con engaño se encuentre contractualmente asegurada. Lo anterior lo afirma este autor a partir de un concepto de patrimonio como "un conjunto de valores económicos jurídicamente reconocidos" (p. 12).

${ }^{144}$ LG Mannheim NJW 1977, p. 160 (resolución de 7 de octubre de 1976). En este caso, el supuesto de hecho se refería a un sujeto que, mediante engaño, celebró un contrato de arrendamiento respecto de un departamento, aduciendo que este sería utilizado por su secretaria, en circunstancias que pretendía destinarlo a dar alojamiento a una prostituta. El LG consideró que la víctima había sido perjudicada en su expectativa de arrendar los restantes departamentos de que era propietaria a un precio normal de mercado, toda vez que la generalidad de las personas no celebraría un contrato de arrendamiento en tales circunstancias o lo haría a un precio menor que el usual, constatando una puesta en peligro del patrimonio equivalente al perjuicio del $\$ 263$ StGB. No obstante la relevancia del reconocimiento de las expectativas como elementos del patrimonio, puede resultar sin embargo discutible la aplicación del tipo de la estafa a los hechos descritos. Sobre esta resolución, vid. las consideraciones críticas de BEULKE (1977) pp. 1073 ss.

145 BGHSt 19, 37. Cit. por LACKNER (1987) p. 1078.

146 BGHSt 17, 147= BGH NJW 1962, p. 973. Cit. por Cramer (1985) NM 88.

147 OLG Hamm JMBLNRW 1954, 132. Cit. por Cramer (1985) NM 88.

148 WeLZEL (1967) p. 352. Señala este autor en defensa de su postura la decisión jurisprudencial contenida en RGSt 65, 100.
} 
Los partidarios de una fórmula en el sentido de la aprobación jurídica o de la falta de desaprobación señalan por el contrario la necesidad de establecer distinciones en cuanto al origen de la nulidad que afecta la obligación de que se trate. Así, una obligación nula puede constituir un elemento integrante del patrimonio en cuanto tenga un valor económico proveniente de la disposición del deudor a darle cumplimiento y en tanto no se trate de una posición en sí reprobada por el derecho ${ }^{149}$. De este modo, puede resultar comprendida en el concepto de patrimonio una obligación nula o ineficaz en razón de la falta de observancia de una formalidad o por tener uno de los obligados una capacidad negocial disminuida ${ }^{150}$.

Resultarán por el contrario excluidas del patrimonio penalmente protegido aquellas obligaciones en que la nulidad se afirma en razón de su contrariedad a la ley o a la moral y a las buenas costumbres (Arts. 1461, 1466 y 1467 CC, respecto de nuestro ordenamiento jurídico-civil; $\$ \$ 134$ y 138 BGB para el caso alemán) ${ }^{151}$. Así, por ejemplo, no se afirmará la existencia de estafa en el caso de la prostituta que realiza una prestación engañada respecto de la retribución monetaria o en el supuesto en que se obtiene de un sicario la comisión de un delito sobre la base de una remuneración fingida.

En la jurisprudencia alemana más reciente es posible advertir con claridad una tendencia a aplicar correctivos normativos al concepto económico de patrimonio en la línea antes señalada. Así, se ha afirmado por el BGH que, ante el derecho, los servicios de una prostituta no constituyen un elemento patrimonial protegido ${ }^{152}$. Asimismo, el OLG de Hamm ha señalado en su sentencia de 26 de enero de 1989 que el derecho de quien presta un servicio de conversaciones telefónicas eróticas a obtener el pago de la contraprestación monetaria no se encuentra amparado por el tipo de la estafa, toda vez que emana de un contrato nulo por contravenir las buenas costumbres $(\$ 138 \mathrm{BGB})^{153}$. Se señala en dicha resolución que aceptar la aplicación del tipo de la estafa respecto de pretensiones nulas que emanan de negocios jurídicos prohibidos o contrarios a la moral situarían al derecho penal en contradicción con el resto del ordenamiento jurídico ${ }^{154}$.

Con todo, es preciso señalar que un número considerable de autores que sostienen un criterio jurídico-económico tratan separadamente el supuesto de servicios ilícitos o inmorales de aquellos casos en que la víctima realiza engañada una prestación con miras a obtener a su vez una contraprestación ilícita o inmoral (estafa en negocio torpe), negando la posibilidad de aplicar el tipo de la estafa en el primer caso y afirmando su admisibilidad en el segun-

\footnotetext{
149 Cramer (1985) NM 92. En similares términos SAMSON y GÜNTHER (1996) NM 123.

150 CRAMER (1985) NM 92. También en nuestro ordenamiento jurídico puede afirmarse un cierto reconocimiento de estos supuestos, toda vez que se señalan como casos de obligaciones naturales "las contraídas por personas que teniendo suficiente juicio y discernimiento, son, sin embargo, incapaces de obligarse según las leyes, como los menores adultos" (Art. 1470 No 1 CC) y "las que proceden de actos a que faltan las solemnidades que la ley exige para que produzcan efectos civiles" (1470 No 3 CC). Ambos supuestos, pese a tratarse de actos anulables (Art. 1682 CC) son causa suficiente para el pago (Art. 2296 CC) pueden afianzarse (Art. 1472 CC) y admiten novación (Art. 1630 CC).

151 En este sentido CRAMER (1985) NM 92; LACKNER (1987) p. 1078.

152 BGH NStZ 1987, p. 407.

153 OLG Hamm, NJW 1989, p. 2551.

154 OLG Hamm, NJW 1989, p. 2551.
} 
do $^{155}$. Es así que, pese a lo que en su momento afirmó Carrara ${ }^{156}$, se sostiene que la admisibilidad de la estafa en el caso en que un sujeto ha realizado un desembolso de dinero sobre la base de la simulación por parte de la contraparte de una prestación inmoral, contraria a la ley o incluso punible no importa la protección de su "derecho" a obtener la contraprestación jurídicamente reprobada. Por el contrario, el perjuicio reside en la prestación dineraria que ha realizado el sujeto, siendo el dinero una elemento de su patrimonio jurídicamente protegido, aun cuando desde una perspectiva civil no proceda la repetición de lo que se ha entregado por un objeto o causa ilícita (Art. 1468 CC; $\$ 817$ BGB) ${ }^{157}$.

Sin embargo, este tratamiento de los supuestos de estafa en negocio torpe, aunque puede calificarse como dominante dentro de las corrientes mixtas, no es sin embargo unánime. Es así que se sostiene por parte de algunos defensores del concepto jurídicoeconómico que la entrega de elementos patrimoniales para la obtención de prestaciones prohibidas o inmorales debe tratarse como un caso de autoperjuicio consciente por parte de la víctima, toda vez que esta se encuentra advertida de la imposibilidad de obtener el cumplimiento de la prestación ofrecida por la contraparte y ha asumido consiguientemente el riesgo correspondiente, por lo que todo perjuicio que se siga de la disposición patrimonial debe imputarse a la misma víctima ${ }^{158}$.

Por último, para un sector importante de los partidarios del concepto mixto constituye un elemento integrante del patrimonio la posibilidad de aprovechamiento de la fuerza de trabajo a cambio de una retribución dineraria o de otra especie ${ }^{159}$. Esta

155 Welzel (1967) p. 354; MaUrach (1953) p. 253; BleI (1983) p. 236. En España sostiene una postura similar BAJO (2004) aunque no en base a la misma argumentación que la doctrina alemana, sino recurriendo a un criterio de política criminal relativo a evitar el otorgamiento de "carta blanca penal" al defraudador cuando se topa con un sujeto necesitado o carente de escrúpulos (p. 85). Este último autor hace referencia a diversas resoluciones judiciales que indican una tendencia de la jurisprudencia española a admitir la punibilidad en estos supuestos, como el caso clásico de un médico que cobró a una mujer una suma de dinero a cambio de realizarle un aborto, cuando en realidad la víctima no se encontraba embarazada (STS de 29 de diciembre de 1961) así como la condena por estafa al director de una escuela de conductores que recibió dinero a cambio de la falsa oferta de obtener ilegalmente una licencia de conducir (STS de 5 de diciembre de 1992) o el caso de un abogado que consigue de la víctima una suma de dinero a cambio de obtener la liberación ilegal de un preso (STS de 4 de diciembre de 1992).

156 CARRARA ([1859] 1980) \$2346, sostiene por consideraciones éticas que debe negarse la estafa en estos supuestos de negotium turpe, ya que "si la víctima del delito es más despreciable que el que la engaña, la sanción penal no debe prostituirse para protegerla”. Agrega el Maestro de Pisa que la solución contraria importaría a su juicio sancionar al defraudador por no haber dado cumplimiento a su prestación inmoral o prohibida.

157 WeLZEL (1967) p. 354.

158 CRAMER (1985) NM 150. Una solución similar puede encontrarse en SAMSON y GÜNTHER (1996) NM 149, quienes sostienen que el tipo de la estafa no puede proteger el patrimonio cuando en un caso particular es puesto al servicio de un fin ilícito o prohibido, pues la solución contraria conduciría a una contradicción valorativa respecto de la norma jurídico-civil que impide la repetición de lo dado por una causa torpe ( $\$ 817 \mathrm{BGB})$. Sobre el tratamiento de estos supuestos como un caso de autoperjuicio consciente vid. HERZBERG (1972) p. 94 ss.

159 Cramer (1985) NM 96; SAMSON y GÜNTHer (1996) NM 124; LACKNER (1987) p. 1078; Wessels (1996) NM 518; Kolrausch y LANGE (1961) p. 579; MaUrach (1953) p. 250. Se discute, sin embargo, si debe considerarse como elemento patrimonial la fuerza de trabajo en cuanto tal o más bien las concreciones de esta en la forma de un servicio o una prestación laboral. En este último sentido parece inclinarse Welzel (1967) p. 352, al igual que BLEI (1983) p. 218. 
conclusión no merece duda en aquellos casos en que se ha celebrado un contrato de trabajo, toda vez que la prestación laboral se hace parte de una relación jurídica de carácter patrimonial ${ }^{160}$. Sin embargo, a diferencia del concepto económico extremo, las tesis jurídico-económicas excluyen del patrimonio a la fuerza de trabajo en los supuestos en que sirve a un fin inmoral o prohibido, no pudiendo por tanto realizarse su valor económico a través de un negocio jurídico válido ${ }^{161}$. Es así que, volviendo al recurrente ejemplo de la doctrina, no constituye un elemento patrimonial digno de protección la "fuerza de trabajo" del sicario o de la prostituta.

\subsection{CONFIGURACIÓN DEL PERJUICIO PATRIMONIAL}

Al momento de constatar el elemento del perjuicio patrimonial, las tesis mixtas atienden a la consideración económica del patrimonio como una suma de valor y no como una mera acumulación de sus elementos integrantes. En razón de ello, existe una amplia aceptación de la necesidad de dar aplicación al principio de compensación, negándose consecuentemente el perjuicio patrimonial toda vez que, por ingresar un elemento de valor al menos igual a la disposición patrimonial realizada, el saldo total del patrimonio no se vea menoscabado ${ }^{162}$. Como se advierte, no hay divergencias sustantivas respecto de las consideraciones aplicadas por el concepto económico puro para la constatación del perjuicio, nos remitimos a lo ya desarrollado sobre este punto.

\section{TOMA DE POSICIÓN. APLICACIÓN DE UN CONCEPTO MIXTO AL ORDENAMIENTO PENAL CHILENO}

Según el mérito de lo anteriormente expuesto, sostenemos aquí un concepto mixto o jurídico-económico de patrimonio. Hemos visto ya lo inconveniente de la adopción de un criterio jurídico, toda vez que el ámbito de protección de la estafa resulta excesivamente estrecho, negándose reconocimiento a posiciones económicamente valiosas de inmensa relevancia para el tráfico. Al mismo tiempo, aparece por otra parte como desmedidamente amplio al impedir la aplicación del principio de compensación y al dispensar protección a derechos subjetivos carentes de contenido económico. Esto último resulta incompatible con la tipificación del delito de estafa en nuestro ordenamiento punitivo, toda vez que la penalidad se determina en atención a la cuantía de lo defraudado (Art. $467 \mathrm{CP}$ ), lo cual es signo de los criterios de valor económico que tiene en mente el Legislador al momento de configurar el elemento del perjuicio. Según lo

\footnotetext{
160 CRAMER (1985) NM 96. Reconoce este autor que, por el contrario, pueden resultar problemáticos aquellos casos en que falta el falta el vínculo contractual, aunque a su juicio lo decisivo debe ser si la fuerza de trabajo, aplicada en la forma de una disposición concreta, conduce normalmente en el tráfico a una contraprestación económica.

161 Expresamente Cramer (1985) NM 97; SAMSON y GÜNTHER (1996) NM 124; Wessels (1996) NM 518; LACKNER (1987) p. 1078.

162 Cramer (1985) NM 106 ss; SAMSON y GÜNTHER (1996) NM 127; WeSSELS (1996) NM 521; LACKNER (1987) p. 1078, KolrausCH y LANGE (1961) p. 581; Welzel (1987) p. 353; MAURACH (1953) p. 250; BLEI (1983) p. 231.
} 
hemos señalado ya, la teoría jurídica importa asimismo una subjetivización del concepto mismo de perjuicio, dependiendo de la víctima la negación de este por la aceptación de la prestación diversa de aquella contractualmente convenida.

Resulta igualmente inconveniente sostener un concepto económico extremo de patrimonio, toda vez que se dispensa una protección jurídico-penal demasiado extensa. Es así que, al tenor de la teoría económica pura, se incluye en la noción de patrimonio la posesión de origen ilícito, al igual que los negocios con un objeto inmoral o prohibido. Lo anterior tiene por consecuencia una severa afectación del principio de la unidad del ordenamiento jurídico, ya que se introducen graves contradicciones valorativas con las restantes ramas del ordenamiento jurídico.

Un concepto jurídico-económico, en cambio, permite salvar los inconvenientes antes señalados. Por una parte, salvo en su formulación más restrictiva, la protección del tipo de la estafa resulta lo suficientemente amplia como para alcanzar las posiciones económicamente valiosas no condensadas en la forma de derechos subjetivos. El concepto económico del que parte permite la consideración del patrimonio como una unidad de valor, admitiéndose así la aplicación del principio de compensación, con lo cual se evita la subjetivización del concepto de perjuicio y la consiguiente transformación de la estafa en un delito en contra de la libertad de disposición o de la confianza en el tráfico. Al mismo tiempo, la aplicación de correctivos normativos permite salvar las contradicciones valorativas en las que cae el concepto económico extremo, asegurando así la vigencia del principio de la unidad del ordenamiento jurídico.

Sin embargo, la adopción de un concepto jurídico-económico deja subsistente la pregunta acerca de cuál de las sus formulaciones resulta más consistente ${ }^{163}$. La versión más restringida del concepto del concepto mixto, según la cual es necesario que las posiciones económicamente valiosas se manifiesten en la forma de derechos subjetivos, debe rechazarse de plano. Tal como lo adelantamos, a esta formulación le son aplicables los mismos reproches que a la tesis jurídica en lo relativo a la exclusión de posiciones con valor dinerario no expresadas en derechos subjetivos. Según lo destacan Samson y Günther, resulta insatisfactorio el hecho que esta versión más restringida del concepto jurídicoeconómico rechace la inclusión en el ámbito de protección del tipo de la estafa del knowhow relativo a conocimientos económicos o técnicos, al mismo tiempo que protege el derecho contractualmente asegurado relativo a dichos conocimientos técnicos ${ }^{164}$.

${ }_{163}$ En doctrina nacional, los autores que se han decidido por un concepto mixto discrepan en torno a la formulación que se ha de adoptar. Así, YUBERo (1964) p. 38, considera que "solo merecen protección los valores económicos jurídicamente reconocidos". POLITOFf et al. (2004) p. 416, consideran en cambio excluidas del concepto de patrimonio solo aquellas posiciones expresamente reprobadas por el ordenamiento jurídico.

164 SAMSON y GÜNTHER (1996) NM 115. Así, según un ejemplo planteado por estos autores, de seguirse la tesis jurídico-económica restringida, no cometería estafa quien mediante engaño obtiene de un especialista en derecho tributario un esquema de planificación tributaria para una empresa. Satisface en cambio el tipo de la estafa quien obtiene del empresario mediante engaño la cesión del derecho contractualmente asegurado relativo al diseño de dicho esquema tributario. Este ejemplo arroja luz acerca de lo altamente insatisfactorio que resulta el que se dispense o no protección a un mismo elemento por el solo hecho de encontrarse expresado en un derecho subjetivo en el sentido del derecho civil. 
Pese a superar los inconvenientes de esta versión más restringida, la formulación del concepto mixto en torno a la exigencia de protección del ordenamiento jurídico nos parece también excesivamente limitada. Así, por ejemplo, parece conveniente hacer una distinción entre las posibles causas de nulidad de una obligación a efecto de considerarla o no comprendida en el concepto penal de patrimonio, toda vez que nuestro ordenamiento jurídico-civil le otorga cierto reconocimiento a las obligaciones en que la nulidad proviene de una capacidad negocial limitada o de la falta de ciertas formalidades al identificarlas como casos de obligaciones naturales (Art. 1470 No 1 y 3 CC). De este modo, pese a tratarse de obligaciones anulables (Art. $1682 \mathrm{CC}$ ), son causa suficiente para el pago (Art. 2296 CC), pueden afianzarse (Art. 1472 CC) y admiten novación (Art. 1630 CC).

Al tenor de lo anterior, consideramos como incluidos en el concepto de patrimonio todas aquellas posiciones económicas que no se encuentren expresamente reprobadas por el ordenamiento jurídico. Sin embargo, no es necesario que dicha reprobación sea de naturaleza penal ${ }^{165}$. Es suficiente una reprobación proveniente de cualquier otro extremo del ordenamiento jurídico a efecto de excluir una determinada posición económica del patrimonio penalmente protegido por el tipo de la estafa. Así, por ejemplo, no constituyen un elemento patrimonial digno de protección penal los servicios ilícitos o contrarios a la moral y a las buenas costumbres, toda vez que se trata de una obligación que el derecho civil sanciona con la nulidad absoluta en razón de la ilicitud de su objeto (Art. 1461 y 1466 CC), sin que deba tomarse en consideración su atipicidad penal (v. gr., los servicios de una prostituta).

No es obstáculo para afirmar lo anterior lo dispuesto en el Art. 470 No 7 CP, en el que se sanciona "a los que en el juego se valieren de fraude para asegurar la suerte". Se ha sostenido que esta norma da lugar a un reconocimiento por parte del ordenamiento punitivo de una posición que el derecho civil reprueba, toda vez que hay un objeto ilícito en las deudas contraídas en juegos de azar (Art. 1466 CC) ${ }^{166}$. Frente a esta postura, en primer lugar no es evidente que el Legislador se esté refiriendo en este numeral a los juegos de azar ${ }^{167}$. En todo caso, aunque así sea, acertadamente sostiene Etcheberry que las disposiciones civiles que declaran viciadas por objeto ilícitos las obligaciones provenientes de juegos de azar, se refieren a aquellos casos en que la ilicitud proviene exclusivamente de la naturaleza misma del juego, mientras que en el supuesto del Art. 470 No 7 CP no hay verdaderamente un juego de azar, sino solo una falsa representación del mismo ${ }^{168}$.

\footnotetext{
165 La postura contraria parece desprenderse de POLITOFF et al. (2004) p. 440, quienes, a propósito de la estafa relativa a servicios ilícitos, solo le niegan protección a aquellos servicios penalmente punibles. En la doctrina española, GALLEGO (2002) p. 281, considera que forman parte del patrimonio los bienes obtenidos antijurídicamente, excluyendo solo aquellos casos en que dicha antijuridicidad sea a la vez un injusto penal. En nuestra opinión, una postura como esta solo es suficiente para asegurar la ausencia de contradicciones valorativas al interior del ordenamiento punitivo, pero resulta insuficiente al momento de salvar la falta de coherencia que se suscita respecto de las demás ramas del derecho.

${ }^{166}$ En ese sentido POLitoff et al. (2002) p. 448.

167 Tanto es así que LABATUT y ZENTENO (1990) p. 229, entienden que el numeral se refiere exclusivamente a los juegos lícitos, regulados en los artículos 2259 a 2263 CC, y no a los juegos de azar.

168 ETCHEBERry (1997) p. 417.
} 
Sin perjuicio de lo anterior, coincidimos con la corriente dominante en Alemania, al tenor de la cual, a diferencia de lo que ocurre respecto de los servicios ilícitos o inmorales (estafa al sicario o a la prostituta), debe admitirse la estafa en los supuestos de negocios torpes, en los que la víctima se desprende de un elemento patrimonial con la expectativa de recibir a cambio una prestación de contenido inmoral o ilícito que la contraparte ha simulado. En estos casos, se protege no el "derecho" a obtener la contraprestación inmoral o ilícita, sino el elemento patrimonial del cual se ha desprendido la víctima.

Respecto de aquellos autores que sostienen que estos supuestos de estafa en negocio torpe deben tratarse como un caso de autoperjuicio consciente, sin entrar aquí a resolver si la falta de conciencia del autoperjuicio constituye o no un elemento funcional de la estafa, al menos respecto del negotium turpe nuestro Código Penal lo ha considerado como irrelevante. Prueba de ello es la figura agravada del Art. 469 No 5 CP, referida "a los que cometieren defraudación con pretexto de supuestas remuneraciones a empleados públicos, sin perjuicio de la acción de calumnia que a estos corresponda”. Como se advierte, el Legislador no le ha asignado importancia para efectos de excluir la estafa al hecho que, de haber sido efectivas las remuneraciones, implicarían la comisión del delito de cohecho activo (Art. $250 \mathrm{CP})^{169}$. El propósito perseguido por la víctima solo cobrará relevancia respecto de la posibilidad de configurar una tentativa inidónea, la cual será o no punible según la doctrina que a ese respecto se adopte, discusión que se presentará solo en tanto la contraprestación esperada importe la comisión de una acción típica ${ }^{170}$.

\section{BIBLIOGRAFÍA CITADA}

Abeliuk ManaseVich, René (2001): Las obligaciones (Bogotá, Editorial Jurídica de

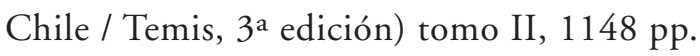

AlesSANDRI RodrígueZ, Arturo (1943): De la responsabilidad extracontractual en el derecho civil chileno (Santiago, Imprenta Universitaria) 716 pp.

Alessandri, Arturo; Somarriva, Manuel; Vodanovic, Antonio (1957): Curso de Derecho Civil. De los bienes (Santiago, Nascimento, 2a edición) 1012 pp.

ANTÓN OneCA, José (1957): Las estafas y otros engaños en el Código Penal y en la jurisprudencia, separata (Barcelona, Editorial Francisco Seix) 34 pp.

\footnotetext{
${ }^{169}$ Entre nosotros, ETCHEBERRY (1997) p. 404 recurre a esta disposición para afirmar en general la punibilidad de la estafa en negocio torpe. En la doctrina española, QUINTANO (1964) p. 628, discurre también en torno a una disposición idéntica a la nuestra existente en la legislación de dicho país previa a la entrada en vigencia del Código Penal de 1995, aunque con un alcance mucho mayor al que aquí proponemos.

170 En este sentido ANTÓN ONECA (1957) p. 13. A nuestro juicio, en la gran mayoría de los casos la falta de peligrosidad para el bien jurídico que representa el mero propósito delictivo de la víctima (se compran polvos inocuos en la creencia de estar adquiriendo medios abortivos, caso del "estafador estafado", etc.) debe conducir respecto de esta a la afirmación de impunidad, solución que consideramos más respetuosa de los criterios objetivos que nuestro CP, enmarcado en la tradición liberal del Código Penal español de 1848, parece haber seguido en el Art 7 CP. Sobre el tratamiento de la tentativa inidónea en general, POLITOFF (1999) p. 133 ss; para su tratamiento a propósito de los supuestos de estafa en negocio torpe y del estafador estafado, BAJO (2004) pp. 88-89.
} 
AsÚA BATARrita, Adela (1993): "El daño patrimonial en la estafa de prestaciones unilaterales (subvenciones, donaciones, gratificaciones). La teoría de la frustración del fin”, ADPCP, Tomo XLVI, Fascículo I: pp. 81-166.

Balmaceda, Gustavo; Preller, Michael Ferdinand (2006): "Análisis dogmático del concepto de perjuicio en el delito de estafa”, REJ, N. ${ }^{\circ} 7:$ pp. 185-217.

Bajo Fernández, Miguel (2004): Los delitos de estafa en el Código Penal (Madrid, Editorial Jurídica Ramón Areces) 184 pp.

BEUlKe, Werner (1977): "Anmerkung (LG Mannheim, Urt. v. 7. 10. 1976 - 2 Ns 98/ 76)”, NJW 1977: pp. 1073-1074.

BINDING, Karl ([1902] 1969): Lehrbuch des Gemeinen Deutschen Strafrech, Besonderer Teil (Aalen, Scientia Verlag, Neudruck der 2. Aufgabe) 362 pp.

BINDING, Karl ([1922] 1991): Die Normen und ibre Übertretung, Band 1, Normen und Strafgesetze (Aalen, Scientia Verlag) 508 pp.

BLEI, Hermann (1983): Strafrecht II. Besonderer Teil (München, C. H. Beck, 12. Auflage) $485 \mathrm{pp}$.

Carrara, Francesco ([1859] 1980): Programa de Derecho Criminal, Parte Especial (Traducc. de José Ortega Torres y Jorge Guerrero, Bogotá, Temis) vol. $4^{\circ}, 549$ pp.

Contreras Torres, Raúl (1966): El delito de estafa (Concepción, Librotec) 115 pp.

CORRal TAlCiAni, Hernán (2004): Lecciones de responsabilidad civil extracontractual (Santiago, Editorial Jurídica de Chile) 423 pp.

Cramer, Peter (1984): \$263, en: SCHÖNKE, Adolf; SCHRÖDER, Horst; et al., Strafgesetzbuch Kommentar (München, Verlag C. H. Beck, 22. Auflage) pp. 1585-1633.

Cramer, Peter (1966): “Grenzen des Vermögenschutzes im Strafrecht”, JuS 1966: pp. 472-477.

Choclán Montalvo, J. A. (2000): El delito de estafa (Barcelona, Bosch) 397 pp.

DAVIS, Pedro (1942): El delito de estafa (Santiago, Memoria de Prueba, Universidad de Chile) $242 \mathrm{pp}$.

DrEHER, Eduard; TRÖNDLE, Herbert (1991): Strafgesetzbuch und Nebengesetze (München, Verlag C. H. Beck, 45. Neuarbeitete Auflage) 1990 pp.

ENNECCERUS, Ludwig; KIPP, Theodor; WOLF, Martin (1948): Tratado de Derecho Civil (Traducc. de la 35a edición alemana de Blas PÉREZ GonZÁlez y José Alguer, Buenos Aires, Bosch) vol. I, 496 pp.

Etcheberry Orthusteguy, Alfredo (1997): Derecho Penal (Santiago, Editorial Jurídica de Chile) tomo III, 490 pp.

FERnÁNDEZ DíAZ, Álvaro (2005): "Engaño y víctima en la estafa”, Revista de Derecho, Pontificia Universidad Católica de Valparaiso, XXVI, Semestre I: pp. 181-193.

Fiandaca, Giovanni; Musco, Enzo (2002): Diritto Penale. Parte Speciale, delitti contro il patrimonio (Bologna, Zanichelli Editore, Seconda Edizione) vol. II, tomo II, I, $282 \mathrm{pp}$.

FUeyo LANerI, Fernando; FigueroA YÁNEEZ, Gonzalo (2004): Cumplimiento e incumplimiento de las obligaciones (Santiago, Editorial Jurídica de Chile) 650 pp.

GALlego SOlER, José Ignacio (2002): Responsabilidad penal y perjuicio patrimonial (Valencia, Tirant lo Blanch) 477 pp. 
GALlAS, Wilhelm (1961): "Der Betrug als Vermögensdelikt", en: BocKELMANN, Paul; GALLAS, Wilhelm (edit.), Festschrift für Eberhard Schmidt zum 70. Geburtstag (Göttingen, Vandenhoeck \& Ruprecht) pp. 401-436.

GÖSSEL, Karl-Heinz (1996): Strafrecht. Besonderer Teil, Band 2. Straftaten gegen materialle Rechtsgüter des Individuums (Heidelberg, C. F. Müller Verlag) 639 pp.

Hedemann, Justus-Wilhelm (1958): Derecho de obligaciones (Traducc. de Jaime SANTOS BRIZ, Madrid, Editorial Revista de Derecho Privado) 612 pp.

Hernández BASUALTO, Héctor (2003): “Aproximación a la problemática de la estafa”, en: VV. AA., Problemas actuales de Derecho Penal (Temuco, Universidad Católica de Temuco) pp. 148-190.

HERZBERG, Rolf-Dietrich (1972): “Bewußte Selbstschädigung beim Betrug”, $M D R$ 1972: pp. 93-97.

HuerTa TOCILDO, Susana (1980): La protección penal del patrimonio inmobiliario (Madrid, Civitas) 187 pp.

JAGUSCH, Heinrich (1958): “\$263”, en: JAGUSCH, Heinrich (Hrsg.), Strafgesetzbuch. Leipziger Kommentar, Volumen II (Berlin, Walter de Gruyte, 8. Auflage) 886 pp.

JAKOBS, Günther (1977): "Die objektiv-individuelle Schadensermittlung beim BetrugOLG Köln, NJW, 1976, 1222”, JuS 1977: pp. 228-232.

JesCHeCK, Hans-Heinrich (1993): Tratado de Derecho Penal. Parte General (Traducc. de la 4 a edición alemana por J. L. ManZanares Samaniego, Granada, Comares) 913 pp.

Kaufmann, Armin ([1954] 1977): Teoría de las normas. Fundamentos de la dogmática penal moderna (Traducc. de Enrique BACIGALUPO y Ernesto GARZÓN VALDÉS, Buenos Aires, Depalma) 403 pp.

KOlRausCH, Eduard; LANGE, Richard (1961): Strafgesetzbuch mit Erläuterungen und Nebengesetzen (Berlin, Walter de Gruyter, 43. Auflage) 788 pp.

KREY, Volker (1995): Strafrecht. Besonderer Teil (Stuttgart-Berlin-Köln, Kohlhammer, 10. Auflage) 296 pp.

Labatut Glena, Gustavo; Zenteno, Julio (1990): Derecho Penal. Parte Especial (Santiago, Editorial Jurídica de Chile) 263 pp.

LACKNER, Karl (1987): Strafgesetzbuch mit Erläuterungen (München, Verlag C. H. Beck, 17. neuarbeitete Auflage) 1468 pp.

LOEWENWARTER, Victor (1935): Derecho Civil Alemán (Santiago, Universidad de Chile) tomo I, $383 \mathrm{pp}$.

MAURACH, Reinhart (1953): Deutsches Strafrecht. Besonderer Teil (Karlsruhe, Verlag C. F. Müller) 596 pp.

MERKEL, Adolf (1867): Kriminalistische Abhandlungen (Leipzig, Breitkopf und Härtel) $339 \mathrm{pp}$.

Muñoz Conde, Francisco (2004): Derecho Penal. Parte Especial (Valencia, Tirant lo Blanch) $1078 \mathrm{pp}$.

NAUCKE, Wolfgang (1964): Zur Lehre vom strafbaren Betrug. Ein Beitrag zum Verhältnis von Strafrechtsdogmatik und Kriminologie (Berlin, Duncker \& Humblot) 259 pp.

Oтто, Harro (1995): Grundkurs Strafrecht. Die einzelnen Delikten (Berlin-NewYork, Walter de Gruyter, 4. Auflage) 528 pp. 
PASTOR Muñoz, Nuria (2004): La determinación del engaño típico en el delito de estafa (Madrid, Marcial Pons) 315 pp.

Politoff, Sergio; Matus, Jean Pierre; RamíreZ, Cecilia (2004): Lecciones de Derecho Penal chileno. Parte Especial (Santiago, Editorial Jurídica de Chile) 689 pp.

POLITOFF, Sergio (1999): Los actos preparatorios del delito, tentativa y frustración (Santiago, Editorial Jurídica de Chile) 276 pp.

Quintano Ripollés, Antonio (1964): Tratado de la Parte Especial del Derecho Penal (Madrid, Editorial Revista de Derecho Privado) tomo II, 1094 pp.

SAMSON, Erich; GÜNTHER, Hans-Ludwig (1996): "\$ 263", 22. Abschnitt, en: VV. AA., Systematischer Kommentar zum Strafgesetzbuch. Besonderer Teil (Köln, Luchterhand, 5. Auflage) NM 99-176.

SAVIGNY, Fridedrich Karl von ([1803]1870): Traité de la possession en droit romain (Traducc. Henri Stadtler, Paris, A. Durand \& Pedone Lauriel) 766 pp.

SCHLACK, Andrés (2007): "Aplicación de criterios objetivo-individuales en la constatación del perjuicio patrimonial en el delito de estafa", Ius Publicum, N. ${ }^{\circ}$ 19: pp. 133146.

TuHR, Andreas von (1910-1918): Der Allgemeine Teil des Deutschen Bürgerlichen Rechts, Zweiter Band, Zweite Hälfte (München-Leipzig, Verlag von Duncker \& Humblot) 652 pp.

Welzel, Hans (1967): Das Deutsche Strafrecht (Berlin, Walter de Gruyter, 10. Auflage) $568 \mathrm{pp}$.

Wessels, Johannes (1996): Strafrecht. Besonderer Teil, Band 2 (Heidelberg, C. F. Müller Verlag, 19. überarbeitete Auflage) 215 pp.

Yubero Cánepa, Julio (1964): Relevancia del engaño en el delito de estafa (Santiago, Memoria de Prueba, Pontificia Universidad Católica de Chile) 92 pp.

\section{NORMAS CITADAS}

- Código Penal de la República de Chile (CP)

- Código Civil de la República de Chile (CC)

- Strafgesetzbuch (Código Penal de la República Federal Alemana, StGB)

- Bürgerliches Allgemeines Gesetzbuch (Código Civil de la República Federal Alemana, BGB)

\section{JURISPRUDENCIA CITADA}

- Entscheidungen des Reichsgericht in Strafsachen 16, $1^{171}$

- Entscheidungen des Reichsgericht in Strafsachen 44, 230

- Entscheidungen des Reichsgericht in Strafsachen 44, 232

- Entscheidungen des Reichsgericht in Strafsachen 65, 3

- Entscheidungen des Reichsgericht in Strafsachen 66, 285

${ }^{171}$ Sentencias del Tribunal Supremo del Imperio Alemán en materia penal, citadas por tomo y página. 
SChlack Muñoz, Andrés "El concepto de patrimonio y su contenido en el delito de estafa"

- Entscheidungen des Reichsgericht in Strafsachen 71, 334

- Entscheidungen des Reichsgericht in Strafsachen 74, 316

- Landgericht ${ }^{172}$ Mannheim, Neue Justizministerialblatt für das Land NordrheinWestfalen, 1977, 160

- Oberlandesgericht ${ }^{173}$, Hamm Justizministerialblatt für das Land Nordrhein-Westfalen 1954,132

- Oberlandesgericht Köln, Neue Juristische Wochenschrift 1959, 1980

- Oberlandesgericht Köln, 1979, 1419

- Oberlandesgericht Köln, Neue Juristische Wochenschrift 1972, 1823

- Oberlandesgericht Karlsruhe, Neue Juristische Wochenschrift 1980,1762

- Oberlandesgericht Düsseldorf, Neue Juristische Wochenschrift 1990, 2397

- Oberlandesgericht Hamm, Neue Juristische Wochenschrift 1989, 2551

- Bundesgerichgerichtshof ${ }^{174}$, Neue Juristische Wochenschrift 1955, 54

- Bundesgerichgerichtshof, Neue Juristische Wochenschrift 1961, 1876

- Bundesgerichgerichtshof, Neue Juristische Wochenschrift 1962, 973

- Entscheidungen des Bundesgerichgerichtshof in Strafsachen ${ }^{175}$ 16, 220

- Entscheidungen des Bundesgerichgerichtshof in Strafsachen 17, 147

- Entscheidungen des Bundesgerichgerichtshof in Strafsachen 19, 37

- Entscheidungen des Bundesgerichgerichtshof in Strafsachen 47, 1

- Bundesgerichtshof, Neue Zeitschrift für Strafrecht 1987, 407

172 Corte de primera instancia de jurisdicción general.

173 Corte de Apelaciones.

174 Tribunal Supremo Federal Alemán.

175 Sentencias del Tribunal Supremo Federal Alemán en materia penal, citadas por tomo y página. 